\title{
Mathematical modeling and analysis of WEDM machining parameters of nickel-based super alloy using response surface methodology
}

\author{
M P GARG ${ }^{1}$, ANISH KUMAR ${ }^{2, *}$ and C K SAHU ${ }^{2}$ \\ ${ }^{1}$ Department of Mechanical Engineering, D.A.V. University, Jallandhar 144001, India \\ ${ }^{2}$ Department of Mechanical Engineering, Maharishi Markandeshwar University, Mullana-Ambala 133207, India \\ e-mail: mpgargacad@gmail.com; anish_kaushik@rediffmail.com; caitanyaksahu@gmail.com
}

MS received 21 May 2016; revised 2 November 2016; accepted 26 December 2016

\begin{abstract}
Inconel 625 is one of the most versatile nickel-based super alloy used in the aerospace, automobile, chemical processing, oil refining, marine, waste treatment, pulp and paper, and power industries. Wire electrical discharge machining (WEDM) is the process considered in the present text for machining of Inconel 625 as it can provide an effective solution for machining ultra-hard, high-strength and temperature-resistant materials and alloys, overcoming the constraints of the conventional processes. The present work is mainly focused on the analysis and optimization of the WEDM process parameters of Inconel 625. The four machining parameters, that is, pulse on time, pulse off time, spark gap voltage and wire feed have been varied to investigate their effects on three output responses, such as cutting speed, gap current, and surface roughness. Response surface methodology was used to develop the experimental models. The parametric analysis-based results revealed that pulse on time and pulse off time were significant, spark gap voltage is the least significant, and wire feed as a single factor is insignificant. Multi-objective optimization technique was employed using desirability approach to obtain the optimal parameters setting. Furthermore, surface topography in terms of machining parameters revealed that pulse on time and pulse off time significantly deteriorate the surface of the machined samples, which produce the deeper, wider overlapping craters and globules of debris.
\end{abstract}

Keywords. WEDM; cutting speed; gap current; surface roughness; desirability; surface topography.

\section{Introduction}

As the world is rapidly progressing in various technical fields such as aerospace, missile, and nuclear industry, very complex and precise components having specific requirements are demanded by these industries. A rapid growth in the development of harder and difficult-to-machine metals, alloys, and super-alloys such as Inconel, Hastelloy, Nitralloy, Nimonics, and Carbide has been noticed. The formidable challenges posed by the demand for economic machining of these ultra-hard, high-strength, high-temperature-resistant and difficult-to-machine metals and alloys to exacting tolerances and surface finish call for development of some special machining techniques. Among the Ni-based super alloys, Inconel 625 is reputed to be one of the most versatile materials owing to its wide application in various industries. It has been more than half a century since the original research and development that led to the invention of Inconel 625. Originally intended for ultra-critical steam piping, the alloy continues to find new application and increased volume of production annually. Inconel 625 has proven to be a valuable and versatile material capable of

*For correspondence solving a variety of design and application problems. In addition to the original goal of a material for main steam line piping, it has been used extensively in the aerospace, automobile, chemical processing, oil refining, marine, waste treatment, pulp and paper, and power industries. As an indication of its versatility, slight modification in composition and mill practice has dramatically increased the fatigue life of thin sheets, thereby increasing the design capabilities in critical turbine components. The excellent weldability of the alloy and its ability to accommodate dilution from other compositions has rendered it a useful filler metal for dissimilar welding. Thus, Inconel 625 can be credited for having an impressive past and significant present, promising a better future. Inconel 625 (or Alloy 625, UNS designation No 6625) is an austenitic Ni-based super alloy with excellent resistance to oxidation and corrosion over a broad range of conditions, including aerospace and chemical process application. The outstanding strength and toughness of Inconel 625 at temperatures ranging from cryogenic to $2000^{\circ} \mathrm{F}\left(1093^{\circ} \mathrm{C}\right)$ are derived, primarily from the solid solution strengthening of refractory metals $\mathrm{Nb}$ and $\mathrm{Mo}$ in a Ni-Cr matrix. The elements $\mathrm{Cr}$ and $\mathrm{Ni}$ contribute to the alloy's outstanding corrosion resistance in oxidizing environments, while Mo and Ni resist any form of non- 
oxidizing corrosion $[1,2]$. These alloys are highly resistant to chloride-stress corrosion cracking and oxidation at high temperature. The high ductility of Inconel 625 is responsible for its ability to withstand solidification and contraction after welding thereby reducing the possibility of cracking. This non-magnetic alloy can be used for parts requiring both corrosion and oxidation resistance up to $2000^{\circ} \mathrm{F}\left(1093^{\circ} \mathrm{C}\right)$, as is the case with jet engine hot zone assemblies. Inconel 625 is a material of choice for gas turbine engine ducting, combustion liners, furnace hardware, spray bars, and special sea water application in aerospace, chemical, petrochemical, and marine industries $[3,4]$. Other applications of Inconel 625 include aeroengine turbine shroud rings and turbine seals, nuclear water reaction components, bellows and expansion joints, and pollution control equipments. Although it is one of the most desirable materials in the aerospace, nuclear, and petrochemical industries, yet from the manufacturing standpoint, it poses serious challenges due to its difficult-to-machine nature causing metallurgical damages to the work piece due to the very high cutting forces, which leads to work hardening, surface tearing, and distortion in the final machined components. During the conventional machining process, intense friction is generated at the tool-work piece interface and the lower thermal conductivity of the alloy results in severe plastic deformation in the local area of work piece due to the excessive heat generation. This effect, coupled with work hardening, results in debonding of the tool substrate, which leads to a series of flaws, such as surface roughness, tool wear, frequent tool changes, short tool life, low productivity, and large amount of power consumption. These difficulties led to the development of newer concepts in metal machining. The newer machining processes, so developed, are often called "modern machining processes" or "unconventional machining methods" as conventional tools are not employed for metal cutting; instead, machining energy in its direct form (e.g. mechanical, electrochemical, chemical, or thermoelectric) is utilized [5]. Wire electrical discharge machining (WEDM), which is considered in the present text for machining of Inconel 625 , is a production process utilizing thermoelectric energy as its fundamental machining energy. WEDM uses electro-thermal mechanism to cut electrically conductive materials. The mechanism of material removal in WEDM is based on the melting and evaporation of materials. It involves the electro-discharge (or spark erosion) effect by voltage pulses generated by a pulse generator as shown in figure 1 . WEDM employs a continuously moving electrode in the form of a wire. The wire is moving on the spool, feeds through the work piece, and is taken up on a second spool. The wire electrode is made of different materials (copper, brass, zinc coated, diffusion annealed, etc.) of diameter ranging from 0.05 to $0.35 \mathrm{~mm}$. The gap between the wire and the work piece is flooded with de-ionized water, which acts as a dielectric. There is no mechanical contact between the wire and the work piece in WEDM. The gap between the wire and the work piece usually ranges from 0.025 to $0.050 \mathrm{~mm}$ and is continuously maintained by a computercontrolled positioning system. The wire is kept under tension by tensioning device to overcome the inaccuracies in the machined parts and is guided by two support members juxtaposing with the work piece. The material is removed by a series of electrical discharges. The wire is kept straight by a mechanical tensioning device and is fed into the work piece by a numerically controlled mechanism or a microprocessor. A varying degree of taper ranging from $15^{\circ}$ for a 100 -mm-thick to $30^{\circ}$ for a 400 -mm-thick work piece can be obtained on the cut surface using microprocessor control.

\section{Literature review}

Prior to undertaking an investigation in the field of WEDM, it is imperative to acquaint oneself with the existing literature in the appropriate field. Over the years, several researchers have revealed various facts associated with the complex process of WEDM that involves a large number of process variables. WEDM has become one of the most sought-after options for precision machining and complicated shape processing in modern tool room industries. Because of the numerous advantages it offers, WEDM has remained a competitive, advanced machining choice in the manufacturing industries. Several authors have come up with their research findings and recommendations regarding development of the WEDM process as well as its ultimate goal of process optimization in order to improve machining efficiency, accuracy, and productivity. A significant amount of experimental investigations have demonstrated the influence of WEDM process parameters on the output responses for a wide range of work materials, composites, and alloys. The literature also highlights the process optimization with respect to various output responses of the WEDM process. Singh and Singh [3] demonstrated the effect of peak current (Ip), pulse on time $\left(T_{\text {on }}\right)$, wire feed rate, and wire tension on the performance measures material removal rate and surface roughness during WEDM of Inconel 625. They concluded that pulse on time is the most controllable effective factor for material removal rate (MRR) and surface roughness, followed by peak current, wire feed rate, and wire tension. Chopde et al [4] investigated the effect of $T_{\mathrm{on}}, T_{\mathrm{off}}$, spark gap voltage (SV), and peak current (Ip) in WEDM of cryotreated AISI $\mathrm{D}_{2}$ steel. Surface roughness ( $\mathrm{Ra}$ ) was considered as the response for improving the surface quality. Taguchi standard Orthogonal Array (OA) was chosen for designing and conducting the experiments. Huang et al [5] analyzed the effect of cutting parameters such as $T_{\text {on }}, T_{\text {off }}$, power, cutting feed rate, wire tension, and water pressure on surface roughness, MRR, and average gap voltage in the WEDM of high hardness tool steel YG 15(WC 85\%, Co 15\%) for both rough cutting and finish cutting. Akbar and Saeed [6] cut 


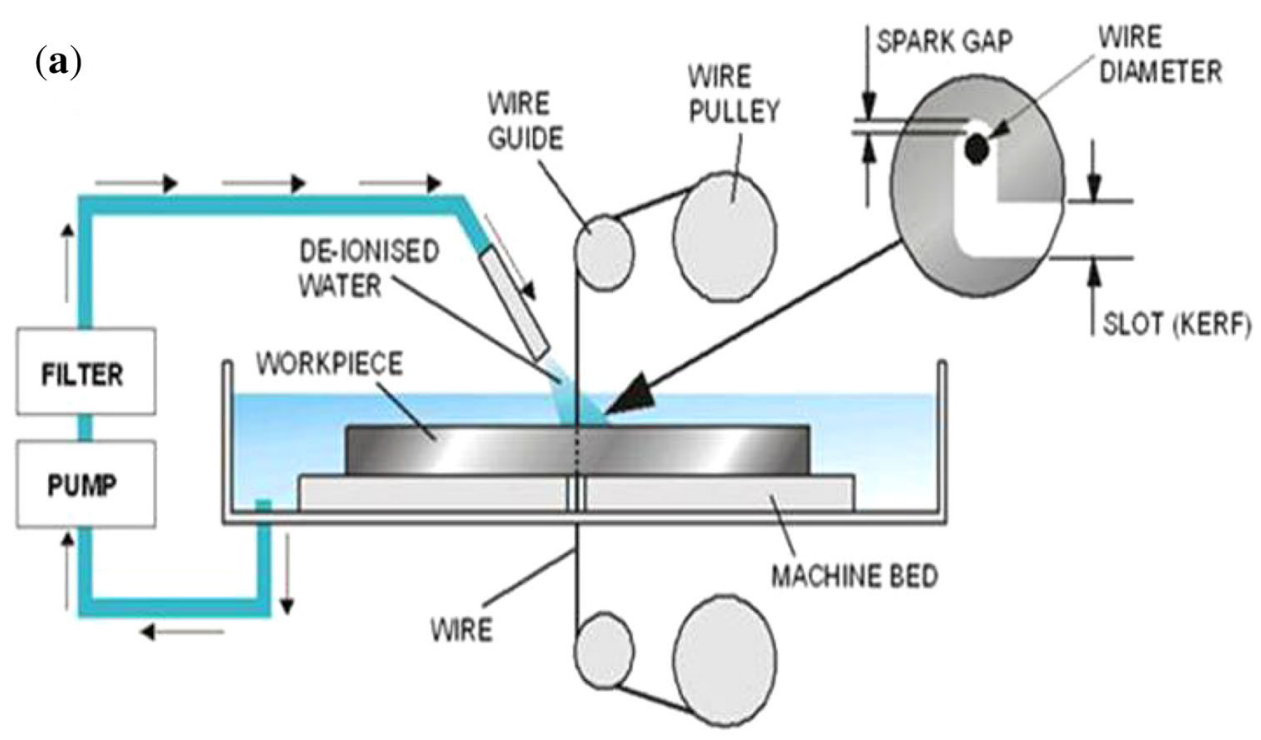

(b)

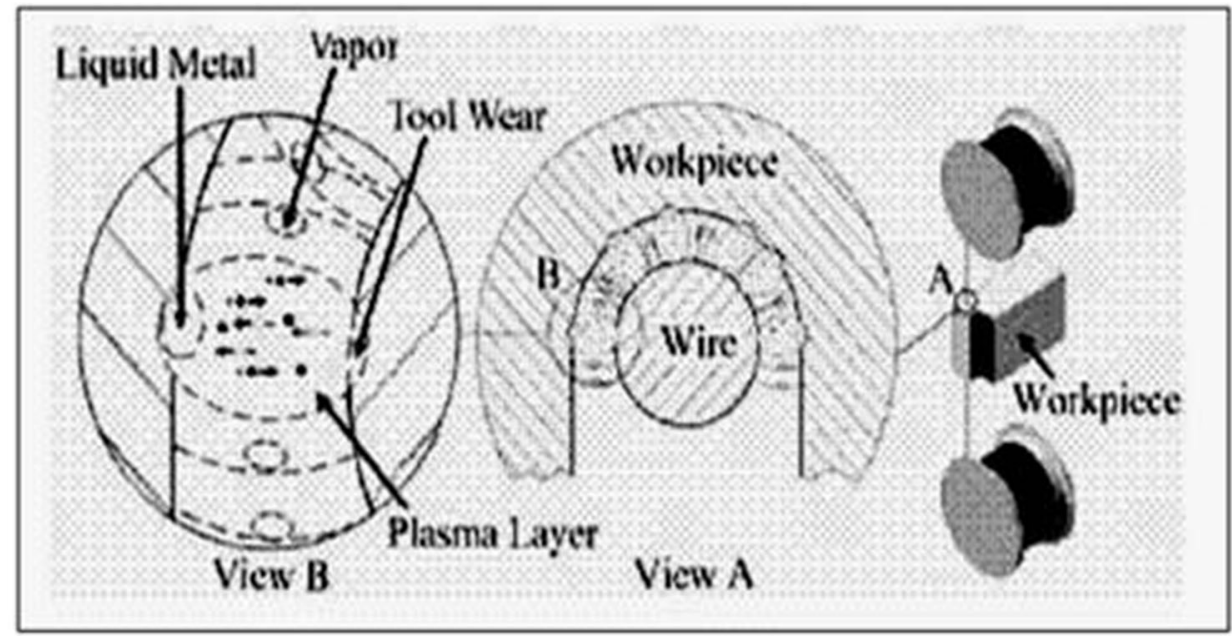

Figure 1. Mechanism of WEDM material removal.

Nitinol-60 shape memory alloy by WEDM using $\mathrm{CuZn}_{37}$ wire and de-ionized water as the dielectric to study the cut surface for changes in the shape recovery ability and micro hardness considering recasting and formation of re-solidified layer. They carried out SEM and X-ray analysis (EDXA, XRD) of the machined surface. EDXA analysis showed phase changes on the cut surface in comparison with base Nitinol metal. XRD analysis showed, besides Nitinol, other phases like $\mathrm{CuZn}, \mathrm{Ti}_{2} \mathrm{Ni}$ inter-metal compound and $\mathrm{NiO}$ and $\mathrm{Cu}_{2} \mathrm{O}$ metal oxides on the cut surface. Zhang et al [7] conducted medium-speed WEDM (wire speed of 10 to $480 \mathrm{~m} / \mathrm{min}$ ) on SKD-11 tool steel using molybdenum wire as tool electrode with an aim to develop a mathematical model to correlate the main process parameters with machining performance and to seek the optimal parameters on MRR and 3-D surface quality by integrated response surface methodology (RSM) and non- dominated sorting algorithm-II. Their experiment demonstrated that the surface quality decreased while the MRR increased with the increase of $T_{\text {on. Narendranath et al [8] }}$ investigated the effect of $T_{\text {on }}$, peak current (Ip), and $T_{\text {off }}$ on WEDM characteristics such as MRR and surface roughness (Ra) on $\mathrm{Ti}_{50} \mathrm{Ni}_{42.4} \mathrm{Cu}_{7.6}$ shape memory alloy using a 0.18 $\mathrm{mm}$ molybdenum wire as electrode. They used RSM-based quadratic models to establish the relationship between process parameters ( $T_{\text {on }}$, Ip and $T_{\text {off }}$ ) and WEDM responses (surface roughness and MRR). The parametric analysisbased results revealed that lower peak current with prolonged $T_{\text {on }}$ led to lower Ra. However, a combination of lower Ip with low $T_{\text {on }}$ was beneficial for achieving better MRR for machining of shape memory. Gupta and Jain [9] investigated the behavior of surface roughness parameters (avg. roughness $\mathrm{Ra}$ and max. roughness $\mathrm{Rt}$ ) of WEDMed fine-pitch miniature spur gears made of brass with half-hard 
brass wire of $0.25 \mathrm{~mm}$ diameter as tool electrode. Effects of four process parameters (voltage, $T_{\mathrm{on}}, T_{\mathrm{off}}$, and wire feed rate) were studied using the Box-Behnken approach of RSM. The parameters were optimized by desirability analysis. An ANN-based model was developed to predict the $\mathrm{Ra}$ of the WEDMed miniature gears and the results were compared with that of the RSM-based model. Kumar et al [10] developed quadratic models for four response variables, machining rate, surface roughness, dimensional deviation, and wire wear ratio, to correlate the dominant parameters, $T_{\text {on }}, T_{\text {off }}$, peak current (Ip), $\mathrm{SV}$, wire feed, and wire tension in the WEDM process of pure titanium (Tigrade 2) using RSM. They concluded that machining rate was mainly affected by $T_{\text {on }}, T_{\text {off }}$, Ip, and SV. Taweel and Hewid [11] presented the effect of feeding speed, duty factor, water pressure, wire tension, and wire speed on the main factors MRR, TWR, and surface roughness while WEDMing CK-45 steel. They have employed RSM for developing experimental models and X-ray diffraction technique for examining the machined surface. They reported that MRR increased with increase in feeding speed value, duty factor, and water pressure. Effect of wire tension and wire speed on MRR was limited. Garg [12] worked on the effects of various process parameters, namely, $T_{\text {on }}, T_{\text {off }}$, spark gap set voltage, peak current, wire feed, and wire tension on the performance measures such as cutting rate, surface roughness, gap current, and dimensional deviation in the WEDM process of hot die steel H-11. Also an optimal set of process variables that yielded the optimum quality features to machined parts were obtained.

A thorough scrutiny of the previous research efforts indicates that substantial amount of work on different aspects of WEDM has been reflected in the literature. Most of the authors have studied the effects of process variables on different responses during WEDM of commonly used materials and alloys. A few works [13-19] have also been reported regarding WEDM of Inconel family of super alloys, such as Inconel 625, Inconel 601, Inconel 718, and Inconel 825.

On the basis of the literature review, the novelty of the present study identified the following gaps with respect to WEDM of Inconel 625.

i. Researchers have investigated the effects of a limited number of process parameters on the response characteristics during WEDM of Inconel 625. Mostly two machining characteristics such as MRR and surface roughness ( $\mathrm{Ra}$ ) have been investigated. No investigation work is available involving gap current as output response in WEDM of Inconel 625. So, gap current can be considered as an output response of the WEDM process.

ii. Predictive modeling for the effects of machining parameters in WEDM of Inconel 625 is another aspect that has not been explored. So, the investigation can be based on predictive models for different responses.

iii. Multi-response optimization of the WEDM process is another thrust area that needed attention. Most researchers have carried out multi-response optimization of the machining characteristics using traditional techniques like the Taguchi method. Hence, some evolutionary optimization technique such as RSM can be employed to arrive at the optimal solutions during optimization of the WEDM process.

iv. Consequently, the need for extension of the existing literature is realized and hence the present work 'WEDM' of 'Inconel 625' is undertaken.

Therefore, it will be interesting to analyze the effects of four basic process parameters (such as pulse on time, pulse off time, SV, and wire feed) on three response characteristics (such as cutting speed, gap current, and surface roughness) in the WEDM of Inconel 625. Further, multiobjective optimization of the responses will also be carried out using RSM to find the optimal solutions.

\section{Experimental procedure}

\subsection{Material and methods}

The experiments were performed on a four-axis CNC type WEDM (Model: Eecocut, Make: Electronica Machine Tools Ltd., Pune, India) as shown in figure 2. The parameters kept constant during machining are shown in table 1 . The chemical composition of work material taken for experimentation was shown in table 2. After WEDM, the metallographic investigations of the machined samples were observed by using inverted metallurgical microscope. The CNC program for machining was generated using ELCAM software. The tool (wire electrode) used in their experiment is half-hard brass wire of $\varnothing 0.25 \mathrm{~mm}$. The work material used is Inconel 625 of dimension $140 \mathrm{~mm} \times 100 \mathrm{~mm} \times 17 \mathrm{~mm}$. A small gap of 0.025 to $0.05 \mathrm{~mm}$ is maintained between the work piece and wire electrode to provide space for proper development of discharge channel for propagation of discharge energy between tool and work piece. Table 3 presents the factors and their levels (table 4). According to experimental design plan as shown in table 5, parameters such as pulse on time, pulse off time, wire feed, and SV were varied to explore their effects on cutting speed, surface roughness, and gap current. Cutting speed is a measure of the rate of cutting operation and is expressed quantitatively in $\mathrm{mm} / \mathrm{min}$. As the machining process is in progress, the instantaneous cutting speed is displayed on the monitor of the machine tool. This instantaneous cutting speed is noted at distances of $2.5 \mathrm{~mm}, 5 \mathrm{~mm}$, and $7 \mathrm{~mm}$ from the initiation of the cut along a particular axis. The same procedure is adopted for 

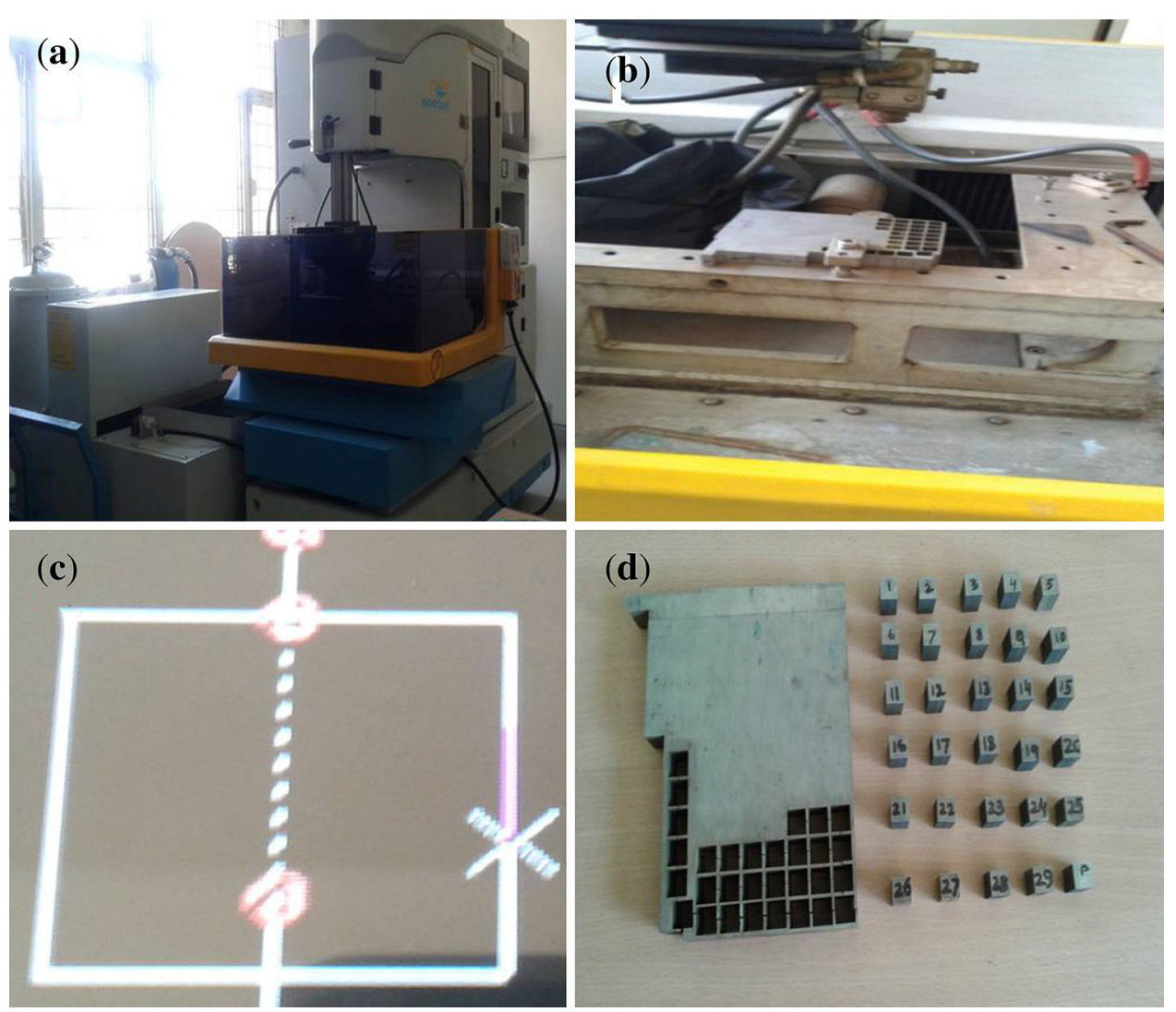

Figure 2. Job profile wire path and experimental set-up of WEDM machine tool. (a) Four-Axis WEDM CNC type, Electronica Eco-cut machine tool, (b) Work piece set-up, (c) Job profile and wire path, and (d) Square punch produced after WEDM.

Table 1. Fixed parameters.

\begin{tabular}{lccc}
\hline S. no. & $\begin{array}{c}\text { Machining } \\
\text { parameters }\end{array}$ & $\begin{array}{c}\text { Fixed operating } \\
\text { conditions }\end{array}$ & Unit \\
\hline 1 & Peak current & 12 & $\mathrm{~A}$ \\
2 & Dielectric pressure & 1 & $\mathrm{~kg} /$ \\
& & 1020 & $\mathrm{~cm}$ \\
3 & Wire tension & Inconel 625 & - \\
4 & Work material & $140 \times 100 \times 17$ & $\mathrm{~mm}$ \\
5 & Work material size & Brass $(\varnothing 0.25)$ & $\mathrm{mm}$ \\
6 & Electrode material & Negative & - \\
7 & Electrode polarity & De-ionized water & - \\
8 & Dielectric fluid & & \\
\hline
\end{tabular}

all four sides of the cutting surfaces of the unit. The surface roughness ( $\mathrm{Ra}$ ) of the machined surface was measured, after all the experimental runs were performed, by using a contact-type, stylus-based surface roughness tester Mitutoyo surftest SJ-301 having a cut-off length of $0.8 \mathrm{~mm}$. A pulse of current is applied by the pulse generator (ELPULS 15) through this small gap to initiate a cutting action and the current passes through the material being cut, called as gap current (Ig), and is measured by an ammeter, which is
Table 2. Chemical composition of work piece material (Inconel 625).

\begin{tabular}{lcc}
\hline Elements & Limiting wt $(\%)$ & Composition wt $(\%)$ \\
\hline $\mathrm{Ni}$ & Min 58 & 61.63 \\
$\mathrm{Cr}$ & $20-23$ & 21.16 \\
$\mathrm{Mo}$ & $8-10$ & 9.16 \\
$\mathrm{Nb}+\mathrm{Ta}$ & $3.15-4.15$ & 3.78 \\
$\mathrm{Fe}$ & Max 5 & 3.28 \\
$\mathrm{Co}$ & Max 1 & 0.37 \\
$\mathrm{Si}$ & Max 0.5 & 0.16 \\
$\mathrm{Mn}$ & Max 0.5 & 0.22 \\
$\mathrm{Ti}$ & Max 0.4 & 0.146 \\
$\mathrm{Al}$ & Max 0.4 & 0.109 \\
$\mathrm{C}$ & Max 0.1 & 0.036 \\
$\mathrm{P}$ & Max 0.015 & 0.009 \\
$\mathrm{~S}$ & Max 0.015 & 0.012 \\
\hline
\end{tabular}

an integral part of the machine and is located at the right front panel. It gives an analog reading by an indicator needle (accuracy of $0.5 \mathrm{~A}$ ), while the cutting is in progress. In this study, the surface integrity was analyzed by using an inverted optical metallurgical microscope. 
Table 3. Factors and their levels of experimental design.

\begin{tabular}{|c|c|c|c|c|c|c|}
\hline \multirow[b]{2}{*}{ S. no. } & \multirow[b]{2}{*}{ Symbols } & \multirow[b]{2}{*}{ Input parameters } & \multicolumn{3}{|c|}{ Parameters Level } & \multirow[b]{2}{*}{ Units } \\
\hline & & & Low (-) & Medium (0) & High $(+)$ & \\
\hline 1. & $T_{\text {on }}$ & Pulse on time & 0.85 & 1.1 & 1.35 & $\mu \mathrm{s}$ \\
\hline 2. & $T_{\text {off }}$ & Pulse off time & 18 & 27 & 36 & $\mu \mathrm{s}$ \\
\hline 4. & SV & Spark gap voltage & 40 & 45 & 50 & $\mathrm{~V}$ \\
\hline 5. & WF & Wire feed & 3 & 5 & 7 & $\mathrm{~m} / \mathrm{min}$ \\
\hline
\end{tabular}

Table 4. Box-Behnken designs for four factors.

\begin{tabular}{lccc}
\hline A & B & C & D \\
\hline \pm 1 & \pm 1 & 0 & 0 \\
0 & 0 & \pm 1 & \pm 1 \\
0 & 0 & 0 & 0 \\
\pm 1 & 0 & 0 & \pm 1 \\
0 & \pm 1 & \pm 1 & 0 \\
0 & 0 & 0 & 0 \\
\pm 1 & 0 & \pm 1 & 0 \\
0 & \pm 1 & 0 & \pm 1 \\
0 & 0 & 0 & 0 \\
\hline
\end{tabular}

\section{Results and discussion}

WEDM is a complex process involving a large number of electrical and technological parameters that are decisive in the machining characteristics of the process, affecting the geometrical shape and surface quality of the machined parts. Proper selection of machining parameters is an important step in the WEDM process, which leads to better machining performance. Whereas improperly selected parameters may cause serious problems like short-circuiting of wire, wire breakage, and deterioration in work piece surface quality, thereby imposing certain limitations on the production schedule and also reducing productivity. Due to the very existence of many variables and also due to the multifaceted and stochastic nature of the WEDM process, even a highly skilled operator with a state-of-the-art WEDM machine tool is rarely able to achieve an optimal performance [20]. The problem will be even more complicated in the case of multi-objective optimization. Although the machine tool manufacturer provides machining parameters table to be used during the setting of machining parameters, the process relies heavily on the experience of the operator and sufficient amount of experimental observations. It is rather difficult to utilize the optimal functions of a machine, owing to the involvement of too many adjustable machining parameters. Consequently, classical parameter design at this juncture is ruled out and a viable alternative is sought in terms of accuracy, efficiency, and cost of the process. An efficient way to solve this problem is to determine the relationship between the performance of the process and its controllable input parameters, that is, to model the process through suitable mathematical techniques, which involves detailed experimentation and subsequent analysis of the results.

\subsection{Response surface modeling of WEDM process}

Response surface modeling (RSM) is a combination of mathematical and statistical techniques that are useful for modeling and analysis of problems in which a response of interest is influenced by several variables and the goal is to optimize this response [21].

The design procedure of RSM is as follows [22]:

i. Designing a series of experiments for adequate and reliable measurements of the response of interest.

ii. Developing a mathematical model of the secondorder response surface with the best fittings.

iii. Finding the optimal set of experimental parameters that produce maximum or minimum value of response.

iv. Representing the direct and interactive effects of process parameters in 2-D and 3-D plots.

If all variables are assumed to be measurable, the response surface can be expressed as follows.

$$
y=\mathrm{f}\left(x_{1}, x_{2}, x_{3}, \ldots x_{n}\right)
$$

where $y$ is the output response and $x_{i}$ is the $i$ th independent variable.

The goal is to optimize the response variable $y$. It is assumed that independent variables are continuous and controllable by experiments with negligible errors. It is required to find a suitable approximation for true functional relationship between the independent variables and the response surface.

In RSM, a dependent variable (response variable) is viewed as a surface to which a mathematical model is fitted. Usually, a two-factor interaction or second-order surface is utilized in RSM, which is given by the following equation $[23,24]$.

$$
y=\beta_{0}+\sum_{i=1}^{k} \beta_{i} x_{i}+\sum_{\mathrm{i}=1}^{\mathrm{k}} \beta_{i i} x_{i}^{2}+\sum_{\mathrm{i}<j} \beta_{i j} x_{i} x_{j}+\varepsilon
$$


Table 5. Design matrix and output responses.

\begin{tabular}{|c|c|c|c|c|c|c|c|c|}
\hline \multirow[b]{2}{*}{$\begin{array}{l}\text { Run } \\
\text { order }\end{array}$} & \multirow[b]{2}{*}{$\begin{array}{l}\text { Standard } \\
\text { order }\end{array}$} & \multicolumn{4}{|c|}{ Control factors } & \multicolumn{3}{|c|}{ Output responses } \\
\hline & & $\begin{array}{c}T_{\mathrm{on}} \\
(\mu \mathrm{s})\end{array}$ & $\begin{array}{l}T_{\text {off }} \\
(\mu \mathrm{s})\end{array}$ & $\begin{array}{l}\text { SV } \\
(\mathrm{V})\end{array}$ & $\begin{array}{l}\mathrm{WF}(\mathrm{m} / \\
\min )\end{array}$ & $\begin{array}{l}\text { Cutting speed }(\mathrm{mm} / \\
\min )\end{array}$ & $\begin{array}{l}\text { Gap current (Ig) } \\
(\mathrm{A})\end{array}$ & $\begin{array}{c}\text { Surface roughness Ra } \\
\qquad(\mu \mathrm{m})\end{array}$ \\
\hline 1 & 15 & 0 & -1 & +1 & 0 & 0.85 & 1.55 & 2.88 \\
\hline 2 & 12 & +1 & 0 & 0 & +1 & 0.89 & 1.85 & 2.83 \\
\hline 3 & 1 & -1 & -1 & 0 & 0 & 0.67 & 0.95 & 2.15 \\
\hline 4 & 8 & 0 & 0 & +1 & +1 & 0.6 & 0.93 & 2.49 \\
\hline 5 & 19 & -1 & 0 & +1 & 0 & 0.44 & 0.56 & 2.15 \\
\hline 6 & 18 & +1 & 0 & -1 & 0 & 1.06 & 1.85 & 3.21 \\
\hline 7 & 25 & 0 & 0 & 0 & 0 & 0.75 & 1.38 & 2.45 \\
\hline 8 & 20 & +1 & 0 & +1 & 0 & 0.79 & 1.68 & 2.86 \\
\hline 9 & 29 & 0 & 0 & 0 & 0 & 0.72 & 1.25 & 2.76 \\
\hline 10 & 7 & 0 & 0 & -1 & +1 & 0.81 & 1.52 & 2.77 \\
\hline 11 & 11 & -1 & 0 & 0 & +1 & 0.49 & 0.47 & 1.72 \\
\hline 12 & 3 & -1 & +1 & 0 & 0 & 0.44 & 0.54 & 1.99 \\
\hline 13 & 5 & 0 & 0 & -1 & -1 & 0.82 & 1.2 & 3.07 \\
\hline 14 & 10 & +1 & 0 & 0 & -1 & 0.91 & 1.38 & 3.17 \\
\hline 15 & 14 & 0 & +1 & -1 & 0 & 0.62 & 0.95 & 2.98 \\
\hline 16 & 23 & 0 & -1 & 0 & +1 & 1.1 & 1.55 & 3.14 \\
\hline 17 & 2 & +1 & -1 & 0 & 0 & 1.27 & 1.95 & 3.43 \\
\hline 18 & 22 & 0 & +1 & 0 & -1 & 0.54 & 0.74 & 2.69 \\
\hline 19 & 26 & 0 & 0 & 0 & 0 & 0.69 & 1.2 & 2.99 \\
\hline 20 & 28 & 0 & 0 & 0 & 0 & 0.69 & 1.19 & 2.86 \\
\hline 21 & 27 & 0 & 0 & 0 & 0 & 0.69 & 1.17 & 2.95 \\
\hline 22 & 9 & -1 & 0 & 0 & -1 & 0.47 & 0.85 & 1.92 \\
\hline 23 & 4 & +1 & +1 & 0 & 0 & 0.68 & 1.48 & 3.1 \\
\hline 24 & 24 & 0 & +1 & 0 & +1 & 0.55 & 0.88 & 1.7 \\
\hline 25 & 21 & 0 & -1 & 0 & -1 & 1.128 & 1.65 & 2.28 \\
\hline 26 & 17 & -1 & 0 & -1 & 0 & 0.63 & 0.85 & 1.11 \\
\hline 27 & 16 & 0 & +1 & +1 & 0 & 0.52 & 0.8 & 1.31 \\
\hline 28 & 13 & 0 & -1 & -1 & 0 & 1.18 & 1.71 & 2.82 \\
\hline 29 & 6 & 0 & 0 & +1 & -1 & 0.63 & 1.08 & 1.83 \\
\hline
\end{tabular}

$T_{\text {on }}$, pulse on time; $T_{\text {off }}$, pulse off time; $\mathrm{SV}$, spark gap voltage; WF, wire feed rate.

where $y$ is the output response, $x_{i}$ is the $i$ th control factor, $i=1,2, \ldots k, \beta$ is the regression coefficient, $\varepsilon$ is the random error, and $k$ is the number of factors.

$\beta_{0}$ is a constant and $\beta_{i}, \beta_{i i}, \beta_{i j}$ are the coefficients of linear, quadratic, and cross-product terms. Regression coefficients $\left(\beta_{s}\right)$ are sometimes called partial regression coefficients as they measure the expected change in $y$ per unit change in $x_{i}$ when $x_{j}$ are held constant. The assumed surface $y$ contains linear, squared, and cross-product terms of the variables $x_{i}$. This study employs the Box-Behnken designs for plan of experiments. Box-Behnken designs for four factors can be arranged in orthogonal blocks, as shown in table 4 . In this table, each $( \pm 1, \pm 1)$ combination within a row represents a full $2^{2}$ design. Rows $1,2,4,5$, 7, 8 each, which leads to four combinations of factors. Therefore, total $6 \times 4=24$ experimental runs are obtained in addition to five experimental runs at which all factors are at 0 level. Therefore, total 29 experiments are obtained.

\subsection{Assessment of the adequacy of model fitting}

In this section, appropriateness of the model is investigated and the quality of the fit is ascertained. To check the adequacy of the model, three different tests are performed such as sequential model sum of squares, lack of fit (LOF) tests, and model summary statistics for cutting speed (CS), gap current (Ig), and surface roughness (Ra). The sequential model sum of squares tests in each table shows how the terms of increasing complexity contribute to the model. This test selects the highest-order polynomial where the additional terms are significant and the model is not aliased. Generally, a model with highest F-value and lower $P$-value is selected. The LOF test is a measure of the failure of the model to represent data in the experimental domain at which points are not included in the regression and variations are observed in the model that cannot be accounted by random error. For the model to be fit, this test should indicate insignificant lack of fit. A $P$-value $>0.05$ nullifies 
Table 6. Model adequacy checking for cutting speed.

\begin{tabular}{|c|c|c|c|c|c|c|c|}
\hline Source & Sum of squares & Degree of freedom & Mean square & F-value & \multicolumn{2}{|c|}{ Prob.>F (P-value) } & Remarks \\
\hline \multicolumn{8}{|c|}{ Sequential model sum of squares } \\
\hline Mean & 16.13 & 1 & 16.13 & & & & \multirow{7}{*}{ Suggested } \\
\hline Linear & 1.32 & 4 & 0.33 & 61.46 & & 001 & \\
\hline $2 \mathrm{FI}$ & 0.048 & 6 & $8.014 \mathrm{E}-003$ & 1.79 & & & \\
\hline Quadratic & 0.054 & 4 & 0.014 & 7.26 & & 022 & \\
\hline Cubic & 0.015 & 8 & $1.901 \mathrm{E}-003$ & 1.03 & & & \\
\hline Residual & 0.011 & 6 & $1.842 \mathrm{E}-003$ & & & & \\
\hline Total & 17.58 & 29 & 0.61 & & & & \\
\hline \multicolumn{8}{|c|}{ Lack of fit tests } \\
\hline Linear & 0.13 & 20 & $6.296 \mathrm{E}-003$ & 8.74 & \multicolumn{2}{|c|}{0.024} & \\
\hline $2 \mathrm{FI}$ & 0.078 & 14 & $5.559 \mathrm{E}-003$ & 7.72 & \multicolumn{2}{|c|}{0.0309} & \\
\hline Quadratic & 0.023 & 10 & $2.338 \mathrm{E}-003$ & 3.25 & \multicolumn{2}{|c|}{0.1338} & Suggested \\
\hline Cubic & $8.170 \mathrm{E}-003$ & 2 & $4.085 \mathrm{E}-003$ & 5.67 & \multicolumn{2}{|c|}{0.0679} & \\
\hline Pure error & $2.880 \mathrm{E}-003$ & 4 & $7.200 \mathrm{E}-004$ & & & & \\
\hline Source & Standard deviation & R-squared & Adjusted R-squared & Predicted & squared & PRESS & Remarks \\
\hline \multicolumn{8}{|c|}{ Model summary statistics } \\
\hline Linear & 0.073 & 0.9111 & 0.8962 & 0.8 & & 0.20 & \multirow{4}{*}{ Suggested } \\
\hline $2 \mathrm{FI}$ & 0.067 & 0.9443 & 0.9133 & 0.8 & & 0.25 & \\
\hline Quadratic & 0.043 & 0.9819 & 0.9637 & 0.9 & & 0.14 & \\
\hline Cubic & 0.043 & 0.9924 & 0.9644 & 0.1 & & 1.18 & \\
\hline
\end{tabular}

Table 7. Model adequacy checking for gap current.

\begin{tabular}{|c|c|c|c|c|c|c|c|}
\hline Source & Sum of squares & Degree of freedom & Mean square & F-value & \multicolumn{2}{|c|}{ Prob. $>\mathrm{F}(P$-value $)$} & Remarks \\
\hline \multicolumn{8}{|c|}{ Sequential model sum of squares } \\
\hline Mean & 42.63 & 1 & 42.63 & & & & \multirow{7}{*}{ Suggested } \\
\hline Linear & 4.47 & 4 & 1.12 & 63.01 & & 001 & \\
\hline $2 \mathrm{FI}$ & 0.25 & 6 & 0.042 & 4.46 & & & \\
\hline Quadratic & 0.037 & 4 & $9.179 \mathrm{E}-003$ & 0.96 & & & \\
\hline Cubic & 0.10 & 8 & 0.013 & 2.48 & & & \\
\hline Residual & 0.031 & 6 & $5.198 \mathrm{E}-003$ & & & & \\
\hline Total & 47.53 & 29 & 1.64 & & & & \\
\hline \multicolumn{8}{|c|}{ Lack of fit tests } \\
\hline Linear & 0.40 & 20 & 0.020 & 2.77 & & & \multirow{5}{*}{ Suggested } \\
\hline $2 \mathrm{FI}$ & 0.14 & 14 & 0.010 & 1.42 & & & \\
\hline Quadratic & 0.11 & 10 & 0.011 & 1.48 & & & \\
\hline Cubic & $2.508 \mathrm{E}-003$ & 2 & $1.254 \mathrm{E}-003$ & 0.17 & & & \\
\hline Pure error & 0.029 & 4 & $7.170 \mathrm{E}-003$ & & & & \\
\hline Source & Standard deviation & R-squared & Adjusted R-squared & Predicted & squared & PRESS & Remarks \\
\hline \multicolumn{8}{|c|}{ Model summary statistics } \\
\hline Linear & 0.13 & 0.9130 & 0.8986 & 0.8 & & 0.65 & \multirow{4}{*}{ Suggested } \\
\hline $2 \mathrm{FI}$ & 0.098 & 0.9650 & 0.9456 & 0.8 & & 0.50 & \\
\hline Quadratic & 0.098 & 0.9725 & 0.9451 & 0.8 & & 0.65 & \\
\hline Cubic & 0.072 & 0.9936 & 0.9703 & 0.9 & & 0.41 & \\
\hline
\end{tabular}

the LOF model to the response data and the model can be utilized for prediction of response parameter for $95 \%$ of confidence interval. Model summary statistics gives details about the standard deviation, $\mathrm{R}^{2}$, Adjusted $\mathrm{R}^{2}$, Predicted $\mathrm{R}^{2}$ and Prediction Error sum of squares (PRESS) of the model. Generally, a model with lesser standard deviation, $\mathrm{R}^{2}$ closes to 1 , and smaller value of PRESS is selected [25]. The data related to sequential model sum of squares, LOF tests, and model summary statistics for CS, gap current and surface roughness are shown in tables 6,7 , and 8, respectively. Quadratic model for CS, 2FI model for gap current and surface roughness are suggested after performing the aforementioned three tests. 
Table 8. Model adequacy checking for surface roughness.

\begin{tabular}{|c|c|c|c|c|c|c|c|}
\hline Source & Sum of squares & Degree of freedom & Mean square & F-value & \multicolumn{2}{|c|}{ Prob. $>\mathrm{F}(P$-value $)$} & Remarks \\
\hline \multicolumn{8}{|c|}{ Sequential model sum of squares } \\
\hline Mean & 186.84 & 1 & 186.84 & & & & \multirow{7}{*}{ Suggested } \\
\hline Linear & 5.98 & 4 & 1.50 & 8.37 & & 002 & \\
\hline $2 \mathrm{FI}$ & 2.33 & 6 & 0.39 & 3.56 & & & \\
\hline Quadratic & 0.50 & 4 & 0.12 & 1.19 & & & \\
\hline Cubic & 1.09 & 8 & 0.14 & 2.18 & & & \\
\hline Residual & 0.38 & 6 & 0.063 & & & & \\
\hline Total & 197.11 & 29 & 6.80 & & & & \\
\hline \multicolumn{8}{|c|}{ Lack of fit tests } \\
\hline Linear & 4.10 & 20 & 0.021 & 4.41 & & & \multirow{5}{*}{ Suggested } \\
\hline $2 \mathrm{FI}$ & 1.77 & 14 & 0.13 & 2.72 & & & \\
\hline Quadratic & 1.28 & 10 & 0.13 & 2.74 & & & \\
\hline Cubic & 0.19 & 2 & 0.095 & 2.03 & & & \\
\hline Pure error & 0.19 & 4 & 0.047 & & & & \\
\hline Source & Standard deviation & R-squared & Adjusted R-squared & Predicted & quared & PRESS & Remarks \\
\hline \multicolumn{8}{|c|}{ Model summary statistics } \\
\hline Linear & 0.42 & 0.9420 & 0.9186 & 0.8 & & 6.46 & \multirow{4}{*}{ Suggested } \\
\hline $2 \mathrm{FI}$ & 0.33 & 0.9750 & 0.9256 & 0.9 & & 5.31 & \\
\hline Quadratic & 0.32 & 0.9825 & 0.9551 & 0.92 & & 7.65 & \\
\hline Cubic & 0.25 & 0.9936 & 0.9703 & 0.9 & & 27.51 & \\
\hline
\end{tabular}

Table 9. ANOVA for response surface of reduced quadratic model of cutting speed.

\begin{tabular}{|c|c|c|c|c|c|c|c|}
\hline Source & $\begin{array}{l}\text { Sum of } \\
\text { squares }\end{array}$ & $\begin{array}{l}\text { Degree of } \\
\text { freedom }\end{array}$ & Mean square & $\begin{array}{c}\text { F- } \\
\text { value }\end{array}$ & $\begin{array}{c}\text { Prob. }>\text { F }(P- \\
\text { value })\end{array}$ & Remarks & $\begin{array}{c}\% \\
\text { Contribution }\end{array}$ \\
\hline Model & 1.42 & 6 & 0.24 & 159.56 & $<0.0001$ & Significant & \\
\hline A & 0.50 & 1 & 0.50 & 341.08 & $<0.0001$ & Significant & 34.48 \\
\hline B & 0.68 & 1 & 0.68 & 457.16 & $<0.0001$ & Significant & 46.89 \\
\hline $\mathrm{C}$ & 0.14 & 1 & 0.14 & 93.79 & $<0.0001$ & Significant & 9.65 \\
\hline $\mathrm{B}^{2}$ & 0.051 & 1 & 0.051 & 34.44 & $<0.0001$ & Significant & 3.51 \\
\hline$A \times B$ & 0.032 & 1 & 0.032 & 29.91 & 0.0001 & Significant & 2.20 \\
\hline $\mathrm{B} \times \mathrm{C}$ & 0.013 & 1 & 0.013 & 8.94 & 0.0067 & Significant & 0.89 \\
\hline Residual & 0.033 & 22 & $1.479 \mathrm{E}-003$ & & & & \\
\hline Lack of fit & 0.03 & 18 & $1.647 \mathrm{E}-003$ & 2.29 & 0.2199 & $\begin{array}{c}\text { Not } \\
\text { significant }\end{array}$ & \\
\hline Pure error & $2.88 \mathrm{E}-003$ & 4 & $7.200 \mathrm{E}-004$ & & & & \\
\hline Corrected total & 1.45 & 28 & & & & & \\
\hline Standard deviation & 0.038 & $\mathrm{R}^{2}$ & 0.9775 & & & & \\
\hline Mean & 0.75 & Adjusted $\mathrm{R}^{2}$ & 0.9714 & & & & \\
\hline $\begin{array}{l}\text { Coefficient of } \\
\text { variation }\end{array}$ & 5.16 & Predicted $\mathrm{R}^{2}$ & 0.9520 & & & & \\
\hline PRESS & 0.069 & $\begin{array}{l}\text { Adequate } \\
\text { precision }\end{array}$ & 49.224 & & & & \\
\hline
\end{tabular}

A, pulse on time; B, pulse off time; $\mathrm{C}$, spark gap voltage.

\subsection{Analysis of variance and mathematical models of response characteristics}

Analysis of variance (ANOVA) is performed to statistically analyze the results. ANOVA checks the value of $\mathrm{R}^{2}$ as it explains the ratio of variability explained by the model to the total variability inherent in the observed data of experiments. It also shows adequate precision that measures signal-to-noise ratios. A ratio greater than 4 indicates the model to be fit. Process variables having $P$ value $<0.05$ are considered significant terms for the given response parameters. The backward elimination method eliminates the insignificant terms to adjust the fitted quadratic/2FI models, and in the present work, backward elimination process with $\alpha$ to exit $=0.05$ is used to eliminate the insignificant terms. Backward elimination 


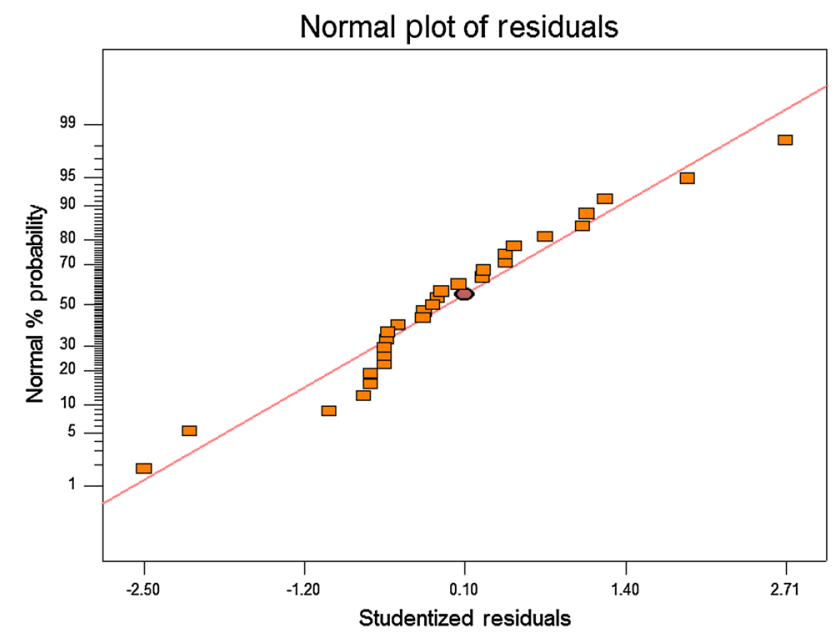

Figure 3. Normal probability plots of residuals for cutting speed.

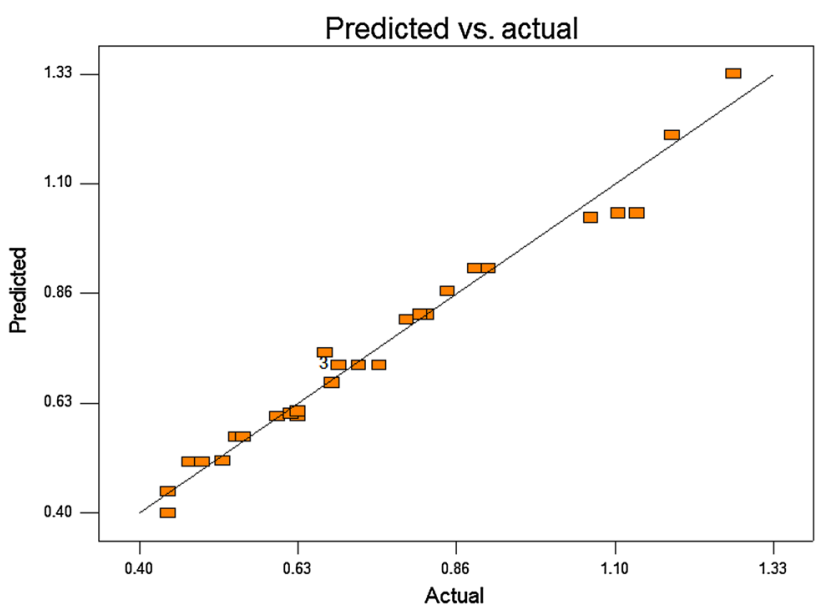

Figure 4. Plot of predicted versus actual of cutting speed data.

starts with fitting the model that includes all $k$ predictors. For each predictor $X_{j}$, compute the F-test statistics that compare the whole model with the reduced model (after excluding $X_{j}$ ). This is repeated for all $X_{i}$. Identify the least significant $X^{*}$ that corresponds to the largest $P$-value associated with the F-test. If this largest $P$-value < $(\alpha=0.05)$, the procedure is stopped and the whole model is claimed as the final model. Otherwise, remove $X^{*}$ from the current model and fit the model to remaining $k$-1 predictors. Next, the least significant predictor is identified and removed by examining the F-test statistics. This is repeated till all the $P$-values in the model are $<\alpha$. The hierarchy of the different models is preserved to develop the mathematical models as it is observed that any hierarchical models are invariant under linear transformation. Principle of hierarchy explains that although a factor as a main effect is found to be insignificant as regards to its contribution toward the response parameter, if its higher- order terms (interaction or quadratic) are significant, the main effect will be included in the analysis as a term of significance. The results and analysis for the three responses to the application of ANOVA test are discussed in the following subsections.

\subsection{Mathematical model for cutting speed}

Quadratic model for cutting speed was recommended, which is shown in table 9 at $95 \%$ confidence level. The model F-value of 159.56 implies the model is significant. There is only a $0.01 \%$ chance that a "Model F-value" this large could occur due to noise. The lack of fit of 0.2199 (which is $>0.05$ ) implies that it is not significant relative to pure error. Thus, quadratic model is significant at $95 \%$ confidence level. The other important coefficient $\mathrm{R}^{2}$, which is called determination coefficient, is defined as the ratio of the explained variation to the total variation and is a measure of the degree of fit. When $\mathrm{R}^{2}$ approaches unity, the response model fits better to the actual data and shows less difference between the predicted and actual value. The obtained value of predicted $R^{2}$ of 0.9520 is in reasonable agreement with the "Adjusted R-squared" of 0.9714 . Normal probability plots of residuals for cutting speed are shown in figure 3. It was observed that it was normally distributed as most of the residuals were clustered around a straight line. It was observed that the regression model fairly well fitted with the observed values. "Adequate Precision" measures the signal-to-noise ratio. A ratio greater than 4 is desirable, we observe an adequate precision of 49.224 (table 8), which indicates an adequate signal. Thus, the quadratic model can be used to navigate the design space. Based on the proposed second-order polynomial model, the effect of the process variables on the cutting speed have been determined and final regression equation for cutting speed in terms of coded factors as follows:

$$
\begin{aligned}
\text { Cutting speed }= & +0.71+0.21 \times \mathrm{A}-0.24 \times \mathrm{B}-0.11 \\
& \times \mathrm{C}+0.085 \times \mathrm{B}^{2}-0.090 \times \mathrm{A} \times \mathrm{B} \\
& +0.058 \times \mathrm{B} \times \mathrm{C}
\end{aligned}
$$

The final regression equation in terms of actual factors is given by

$$
\begin{aligned}
\text { Cutting speed }= & +2.61829+1.9 \times T_{\text {on }}-0.096589 \times T_{\text {off }} \\
& -0.056 \times \mathrm{SV}+1.05035 \mathrm{E}-003 \\
& \times T_{\text {off }}^{2}-0.04 \times T_{\text {on }} \times T_{\text {off }}+1.27778 \mathrm{E} \\
& -003 \times T_{\text {off }} \times \mathrm{SV}
\end{aligned}
$$

The quadratic function of pulse off time ( $\left.T_{\text {off }}\right)$ has a significant effect on the cutting speed and can be used to predict cutting speed within the limits of control factors. All 
Table 10. ANOVA for response surface of reduced quadratic model of gap current.

\begin{tabular}{|c|c|c|c|c|c|c|c|}
\hline Source & $\begin{array}{l}\text { Sum of } \\
\text { squares }\end{array}$ & $\begin{array}{l}\text { Degree of } \\
\text { freedom }\end{array}$ & Mean square & $\begin{array}{c}\text { F- } \\
\text { value }\end{array}$ & $\begin{array}{c}\text { Prob. }>\mathrm{F}(P- \\
\text { value })\end{array}$ & Remarks & $\begin{array}{c}\% \\
\text { Contribution }\end{array}$ \\
\hline Model & 4.71 & 6 & 0.78 & 90.80 & $<0.0001$ & Significant & \\
\hline A & 2.97 & 1 & 2.97 & 343.61 & $<0.0001$ & Significant & 60.61 \\
\hline $\mathrm{B}$ & 1.31 & 1 & 1.31 & 151.95 & $<0.0001$ & Significant & 26.73 \\
\hline $\mathrm{C}$ & 0.18 & 1 & 0.18 & 21.12 & 0.0001 & Significant & 3.67 \\
\hline $\mathrm{D}$ & $7.5 \mathrm{E}-003$ & 1 & $7.5 \mathrm{E}-003$ & 0.87 & 0.3617 & $\begin{array}{l}\text { Not } \\
\text { significant }\end{array}$ & 0.153 \\
\hline $\mathrm{A} \times \mathrm{D}$ & 0.18 & 1 & 0.18 & 20.90 & 0.0001 & Significant & 3.67 \\
\hline $\mathrm{C} \times \mathrm{D}$ & 0.055 & 1 & 0.055 & 6.39 & 0.0192 & Significant & 1.12 \\
\hline Residual & 0.19 & 22 & $8.644 \mathrm{E}-003$ & & & & \\
\hline Lack of fit & 0.16 & 18 & $8.971 \mathrm{E}-003$ & 1.25 & 0.4587 & $\begin{array}{l}\text { Not } \\
\text { significant }\end{array}$ & \\
\hline Pure error & 0.029 & 4 & $7.17-003$ & & & & \\
\hline Corrected total & 4.90 & 28 & & & & & \\
\hline Standard deviation & 0.093 & $\mathrm{R}^{2}$ & 0.9612 & & & & \\
\hline Mean & 1.21 & Adjusted $\mathrm{R}^{2}$ & 0.9506 & & & & \\
\hline $\begin{array}{l}\text { Coefficient of } \\
\text { variation }\end{array}$ & 7.67 & Predicted $\mathrm{R}^{2}$ & 0.9279 & & & & \\
\hline PRESS & 0.35 & $\begin{array}{l}\text { Adequate } \\
\text { precision }\end{array}$ & 36.269 & & & & \\
\hline
\end{tabular}

A, pulse on time; B, pulse off time; C, spark gap voltage; D, wire feed.

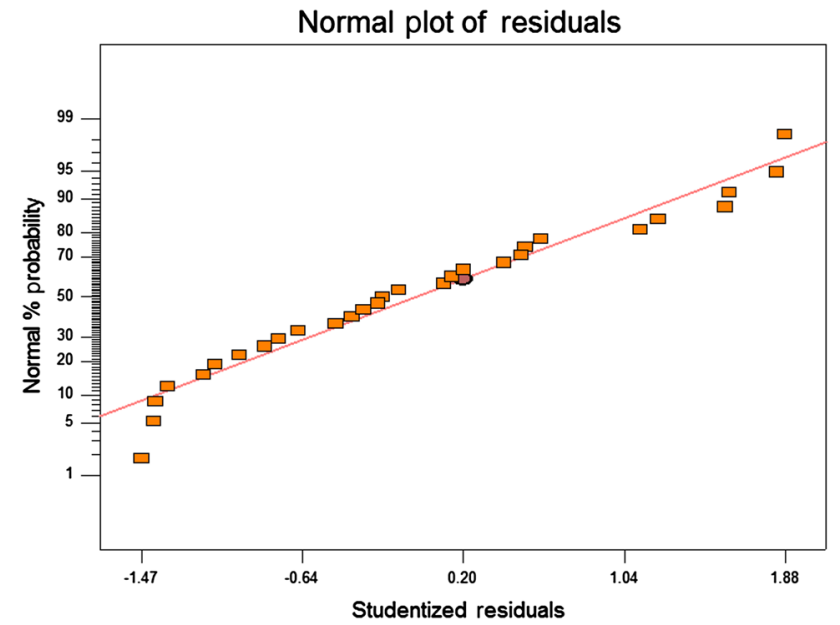

Figure 5. Normal probability plots of residuals for gap current.

the sources having probability (Prob $>F$ ) $<0.05$ represent factors of statistical significance for the response under consideration. In addition to individual factor effects, twofactor interactions are also found to be significant (table 8). Plot of actual (experimental) and predicted data for cutting speed is shown in figure 4. It depicts that Eq. (4) is adequate to represent the actual relationship between process parameters and responses. Almost $81 \%$ of the total variation in the response data could be contributed by factors $T_{\text {on }}$ (A) and $T_{\text {off }}(\mathrm{B})$. In this case, $\mathrm{A}, \mathrm{B}, \mathrm{C}, \mathrm{B}^{2}, \mathrm{AB}$, and $\mathrm{BC}$ are significant model terms.

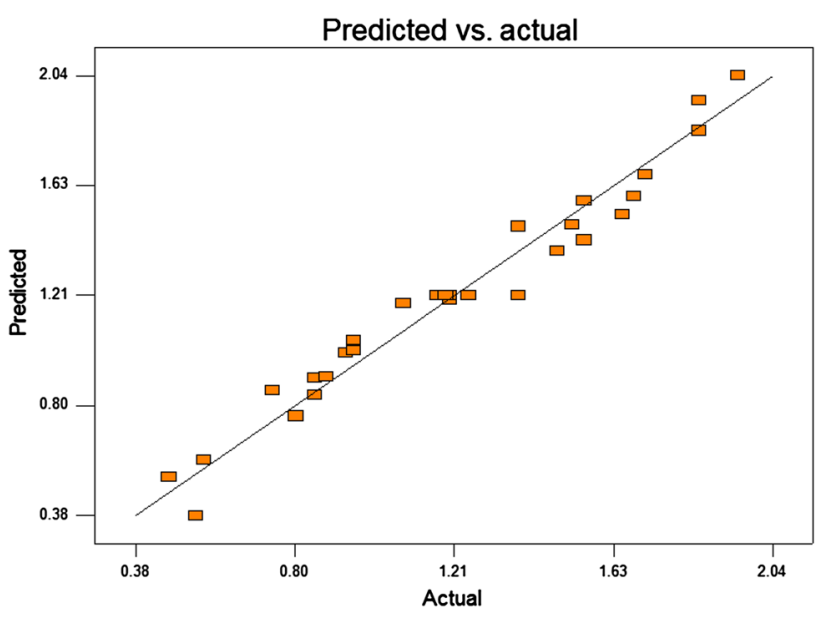

Figure 6. Plot of predicted versus actual of gap current data.

\subsection{Mathematical model for gap current}

Based on ANOVA as shown in table 10, factors $T_{\text {on }}(\mathrm{A})$, $T_{\text {off }}(\mathrm{B}), \mathrm{SV}(\mathrm{C})$, and two interaction terms $T_{\text {on }} \times \mathrm{WF}$ $(\mathrm{A} \times \mathrm{D})$ and $\mathrm{SV} \times \mathrm{WF}(\mathrm{C} \times \mathrm{D})$ are found to be the significant parameters at $95 \%$ confidence level. The data are normally distributed. It is observed that all the experimental results are, approximately, very close to the predicted values are shown in figures 5 and 6 . The "Model F Value" of 90.80 implies the model is significant. There is only a $0.01 \%$ chance that a "Model F Value" this large could occur due to noise. The "Lack of fit F-value" of 1.25 
Table 11. ANOVA for response surface of reduced quadratic model of surface roughness.

\begin{tabular}{|c|c|c|c|c|c|c|c|}
\hline Source & $\begin{array}{l}\text { Sum of } \\
\text { squares }\end{array}$ & $\begin{array}{l}\text { Degree of } \\
\text { freedom }\end{array}$ & Mean square & $\begin{array}{c}\text { F- } \\
\text { value }\end{array}$ & $\begin{array}{l}\text { Prob. }>\mathrm{F}(P- \\
\text { value })\end{array}$ & Remarks & $\begin{array}{c}\% \\
\text { Contribution }\end{array}$ \\
\hline Model & 8.07 & 7 & 1.15 & 10.99 & $<0.0001$ & Significant & \\
\hline $\mathrm{A}$ & 4.76 & 1 & 4.76 & 45.40 & $<0.0001$ & Significant & 46.34 \\
\hline B & 0.72 & 1 & 0.72 & 6.82 & 0.0163 & Significant & 7.01 \\
\hline $\mathrm{C}$ & 0.50 & 1 & 0.50 & 4.73 & 0.0412 & Significant & 4.86 \\
\hline $\mathrm{D}$ & $8.008 \mathrm{E}-003$ & 1 & $8.008 \mathrm{E}-003$ & 0.076 & 0.7850 & $\begin{array}{l}\text { Not } \\
\text { significant }\end{array}$ & 0.07 \\
\hline $\mathrm{A} \times \mathrm{C}$ & 0.48 & 1 & 0.48 & 4.60 & 0.0437 & Significant & 4.67 \\
\hline $\mathrm{B} \times \mathrm{C}$ & 0.75 & 1 & 0.75 & 7.13 & 0.0143 & Significant & 7.30 \\
\hline $\mathrm{B} \times \mathrm{D}$ & 0.86 & 1 & 0.86 & 8.16 & 0.0095 & Significant & 8.37 \\
\hline Residual & 2.20 & 21 & 0.10 & & & & \\
\hline Lack of fit & 2.02 & 17 & 0.12 & 2.55 & 0.1889 & $\begin{array}{c}\text { Not } \\
\text { significant }\end{array}$ & \\
\hline Pure error & 0.19 & 4 & 0.047 & & & & \\
\hline Corrected total & 10.27 & 28 & & & & & \\
\hline Standard deviation & 0.32 & $\mathrm{R}^{2}$ & 0.9855 & & & & \\
\hline Mean & 2.54 & Adjusted $\mathrm{R}^{2}$ & 0.9750 & & & & \\
\hline $\begin{array}{c}\text { Coefficient of } \\
\text { variance }\end{array}$ & 12.76 & Predicted $\mathrm{R}^{2}$ & 0.9193 & & & & \\
\hline PRESS & 4.94 & $\begin{array}{l}\text { Adequate } \\
\text { precision }\end{array}$ & 22.114 & & & & \\
\hline
\end{tabular}

A, pulse on time; B, pulse off time; $\mathrm{C}$, spark gap voltage; $\mathrm{D}$, wire feed.

implies the lack of fit is not significant, relative to the pure error. The predicted $\mathrm{R}^{2}$ of 0.9279 (table 9) is in reasonable agreement with the "Adjusted R-Squared" of 0.9506. The obtained ratio of 36.269 is an adequate signal and it suggests that this model can be used to navigate the design space. The regression equation for the gap current in terms of coded factors is given by

$$
\begin{aligned}
\text { Gap current }= & +1.21+0.50 \times \mathrm{A}-0.33 \times \mathrm{B}-0.12 \times \mathrm{C} \\
& +0.025 \times \mathrm{D}+0.21 \times \mathrm{A} \times \mathrm{D}-0.12 \times \mathrm{C} \\
& \times \mathrm{D}
\end{aligned}
$$

And in terms of actual factors, the equation is modeled as

$$
\begin{aligned}
\text { Gap current }= & +0.75716-0.135 \times T_{\text {on }}-0.036759 \times T_{\text {off }} \\
& +0.034083 \times \mathrm{SV}+0.07357 \times \mathrm{WF} \\
& +0.425 \times T_{\text {on }} \times \mathrm{WF}-0.01175 \times \mathrm{SV} \\
& \times \mathrm{WF}
\end{aligned}
$$

Based on the results of the ANOVA test, it could be observed that factor $T_{\text {on }}$ is the most significant, followed by $T_{\text {off }}$. Together, these two factors contribute $>87 \%$ toward the variation in gap current. Another factor SV and two interaction terms $T_{\mathrm{on}} \times \mathrm{WF}$ and $\mathrm{SV} \times \mathrm{WF}$ are also significant. The predicted values have slight variation around the central line. However, the plot could justify the ability of the model to predict the response with reasonable accuracy as shown in figure 6 .

\subsection{Mathematical model for surface roughness}

Surfaces roughness is an important performance measure that dictates the manufacturing quality of the WEDMed components. If the surface finish of the machined part is the decisive factor due to its application requirements, then the work material must be machined with low cutting speed. Based on ANOVA as shown in table $11, T_{\text {on }}, T_{\text {off }}, \mathrm{SV}$, and three interactions $T_{\text {on }} \times \mathrm{SV}, T_{\text {off }} \times \mathrm{SV}$ and $T_{\text {off }} \times \mathrm{WF}$ are significant to surface roughness. During preparation of the model, non-significant terms are eliminated by backward elimination. The values of "prob $>F$ " $<0.05$ indicates that model terms are significant at $95 \%$ confidence level. Normal probability plot of residuals for surface roughness was shown in figures 7 and 8 . It shows that the data are normally distributed. Most of the residuals are clustered around the straight line, implying that errors are normally distributed. It also indicates that regression model is fairly well fitted with the observed values. The model $\mathrm{F}$ value of 10.99 and associated $P$-value $<0.0001$ (i.e. lower than 0.05 ) indicate that the model is significant. Further, it implies that there is only $0.01 \%$ chance that a "Model $\mathrm{F}$ value" this large could occur due to noise. To fit the quadratic model for surface roughness appropriately, the non-significant terms are eliminated by backward elimination. The $P$-value for lack of fit is 0.1889 , which is $>0.05$ suggesting that the model adequately fits the data. Based on the proposed quadratic process order, the regression equation defining the relation between surface roughness and process parameters in terms of coded factors is given by 


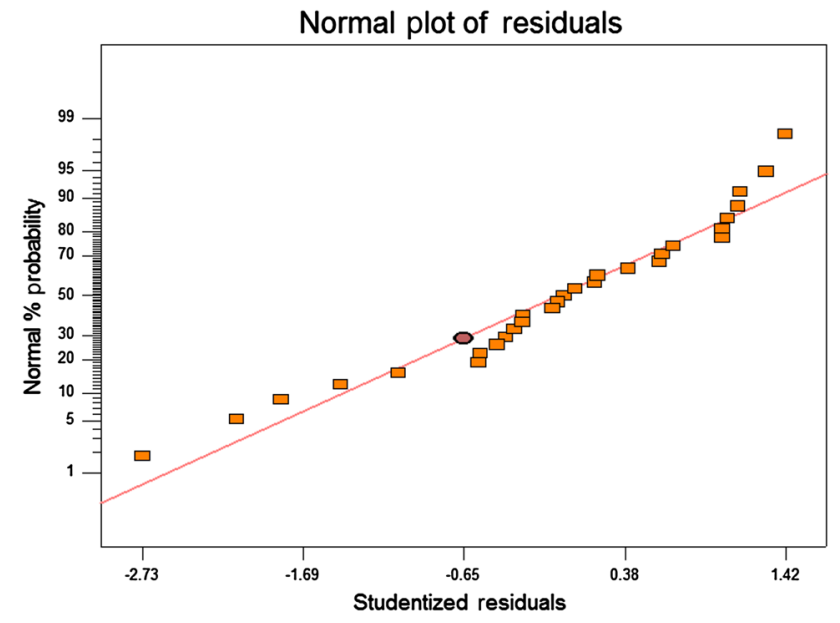

Figure 7. Normal probability plots of residuals for surface roughness.

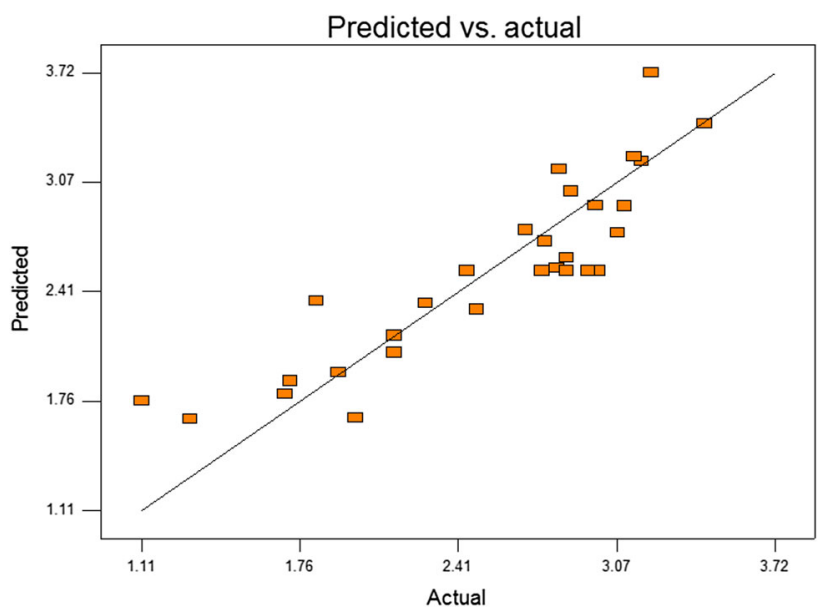

Figure 8. Plot of predicted versus actual of surface roughness data.

$$
\begin{aligned}
\text { Surface roughness }= & +2.54+0.63 \times \mathrm{A}-0.24 \times \mathrm{B} \\
& -0.20 \times \mathrm{C}-0.026 \times \mathrm{D}-0.35 \times \mathrm{A} \\
& \times \mathrm{C}-0.43 \times \mathrm{B} \times \mathrm{C}-0.46 \times \mathrm{B} \times \mathrm{D}
\end{aligned}
$$

In actual factors, the final equation for surface roughness is

$$
\begin{aligned}
\text { Surface roughness }= & -26.51389+15.03 \times T_{\text {on }}+0.53384 \\
& \times T_{\text {off }}+0.52463 \times \mathrm{SV}+0.68083 \\
& \times \mathrm{WF}-0.278 \times T_{\text {on }} \times \mathrm{SV} \\
& -9.61111 \mathrm{E}-003 \times T_{\text {on }} \times \mathrm{SV} \\
& -0.025694 \times T_{\text {off }} \times \mathrm{WF}
\end{aligned}
$$

From the ANOVA results (table 11), it can be seen that factors $\mathrm{A}\left(T_{\mathrm{on}}\right), \mathrm{B}\left(T_{\mathrm{off}}\right)$, and $\mathrm{C}(\mathrm{SV})$ are significant in addition to three interaction terms, namely, $\mathrm{A} \times \mathrm{C}, \mathrm{B} \times \mathrm{C}$, and $\mathrm{B} \times \mathrm{D}$ for Ra. Factor $\mathrm{A}$, that is, pulse on time is the

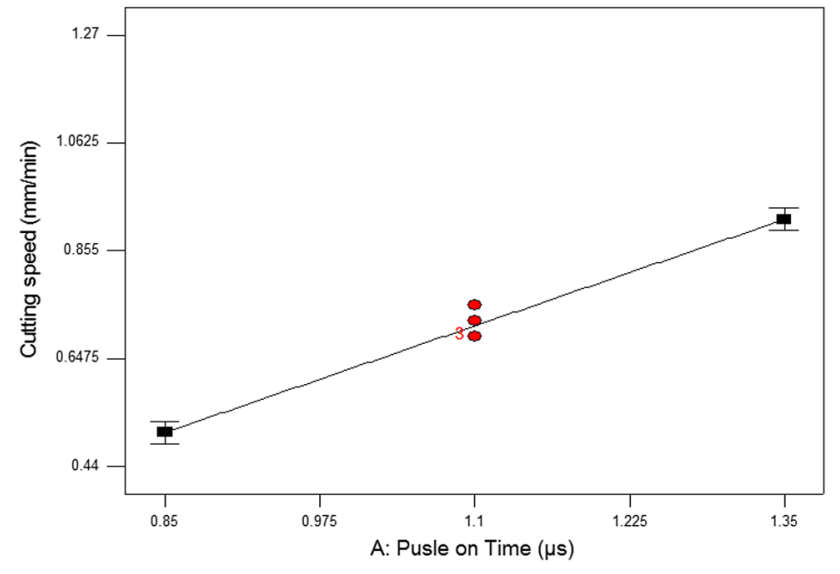

Figure 9. Effect of pulse on time on cutting speed.

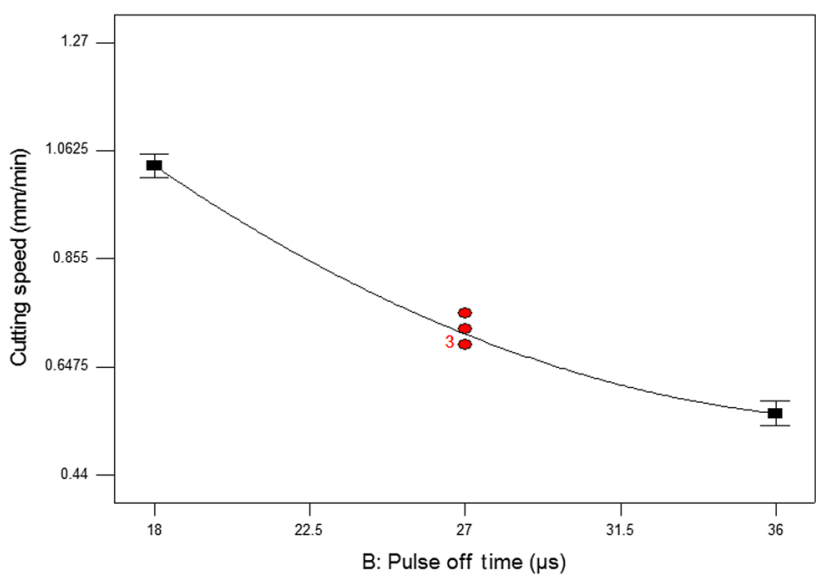

Figure 10. Effect of pulse off time on cutting speed.

most significant process parameter influencing surface roughness with $46.34 \%$ contribution.

\subsection{Effect of process parameters on response characteristics}

This section presents the effects of process parameters on response characteristics such as cutting speed, gap current, and surface roughness. The individual as well as the interaction effects of different process variables on the considered response characteristics have been discussed. The following subsections have given the effects of various parameters on different response characteristics.

4.7a Cutting speed (CS): Based on the main effect plots as shown in figures 9,10 and 11, the cutting speed was mainly affected by $T_{\text {on }}, T_{\text {off }}$, and SV. The cutting speed was increased significantly from 0.505 to $0.915 \mathrm{~mm} / \mathrm{min}(81 \%$ increment) when the pulse on time was increased from 0.85 to $1.35 \mu \mathrm{s}$ as shown in figure 9. This is because higher 


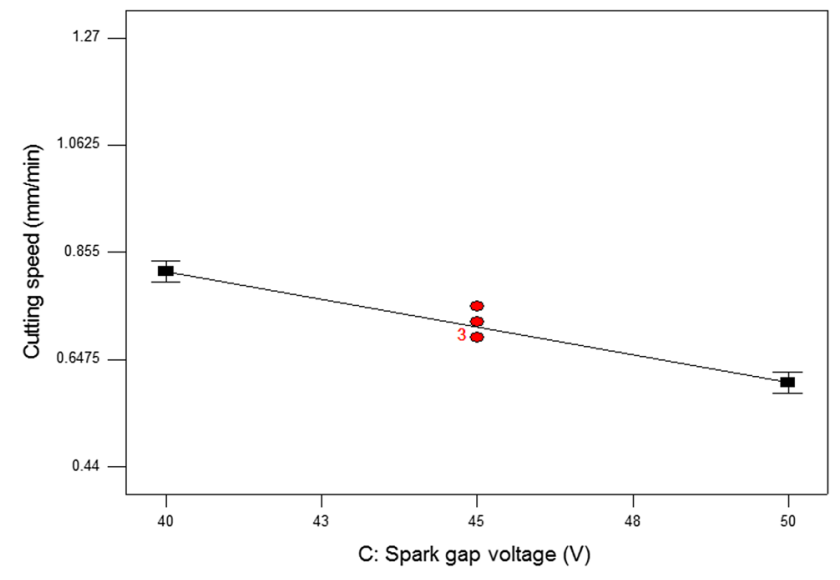

Figure 11. Effect of spark gap voltage on cutting speed.

value of pulse on time increases the single-pulse discharge energy and it leads to rapid melting and evaporation of material, resulting in higher cutting speed. By decreasing the pulse off time from 36 to $18 \mu$ s the cutting speed improved dramatically from 0.558 to $1.033 \mathrm{~mm} / \mathrm{min}(85 \%$ increment), as observed in figure 10 . With a lower value of $T_{\text {off }}$, there are more number of discharges in a given time, resulting in increase of sparking efficiency. As a result, cutting speed increases. Shorter the $T_{\text {off }}$ period, faster will be the machining operation. Also, by decreasing the SV from 50 to $40 \mathrm{~V}$, the cutting speed increased from 0.603 to $0.818 \mathrm{~mm} / \mathrm{min}$ (36\% increment) as observed in figure 11 . The underlying reason is that smaller SV value will narrow down the spark gap (i.e. lower discharge waiting time), leading to a more number of sparks per unit time. It increases the cutting speed. Since pulse on time and pulse off time showed the high percentage contribution as compared to other factors (i.e. SV), they can be considered most significant to cutting speed. The percentage contribution of significant parameters is $T_{\mathrm{on}}=34 \%, \quad T_{\mathrm{off}}=47 \%$, $\mathrm{SV}=10 \%$. Based on table 9, two interaction terms are found to be significant, $T_{\text {on }} \times T_{\text {off }}, T_{\text {off }} \times \mathrm{SV}$ as observed in figures 12 and 13. The "prob. $>$ F" values of $T_{\text {on }} \times T_{\text {off }}$ and $T_{\text {off }} \times \mathrm{SV}$ are 0.001 and 0.0067 , respectively. As "prob. $>$ F" value of the interactions $T_{\text {on }} \times T_{\text {off }}$ is more near to zero, it has higher significance than $T_{\text {off }} \times \mathrm{SV}$. It can be observed that when $T_{\text {off }}$ was set at $36 \mu \mathrm{s}$ and $T_{\text {on }}$ parallel increased from 0.85 to $1.35 \mu \mathrm{s}$, the cutting speed increased by $55 \%$ from 0.44 to $0.68 \mathrm{~mm} / \mathrm{min}$. Whereas, when $T_{\text {off }}$ was set to a lower value of $18 \mu$ s and $T_{\text {on }}$ was increased from 0.85 to $1.35 \mu \mathrm{s}$, cutting speed increased significantly by $80 \%$ from 0.738 to $1.328 \mathrm{~mm} / \mathrm{min}$. The other interaction between $T_{\text {off }}$ and SV can be analyzed when spark gap voltage of $50 \mathrm{~V}$ with $T_{\text {off }}$ was decreased from 36 to $18 \mu \mathrm{s}$, the cutting speed was increased significantly by $71 \%$ from 0.508 to $0.868 \mathrm{~mm} / \mathrm{min}$. Whereas by keeping the SV at $40 \mathrm{~V}$, with $T_{\text {off }}$ was decreased from 36 to18 $\mu$ s, cutting speed was increased dramatically by $97 \%$ from 0.608 to $1.198 \mathrm{~mm} / \mathrm{min}$.

4.7b Gap current (Ig): Based on ANOVA (table 10), $T_{\text {on }}$, $T_{\text {off }}, \mathrm{SV}$, and two interactions $T_{\text {on }} \times \mathrm{WF}$ and $\mathrm{SV} \times \mathrm{WF}$ are significant for gap current (Ig). The main effects plots of $T_{\text {on }}, T_{\text {off }}$, and $\mathrm{SV}$ on gap current are shown in figures 14,15 and 16 , respectively. When pulse on time was increased from 0.85 to $1.35 \mu \mathrm{s}$, the gap current (Ig) value shot up dramatically by $139 \%$ from 0.714 to $1.709 \mathrm{~A}$, as observed in figure 14. On the other hand, figures 15 and 16 showed that on increasing the pulse off time and spark gap voltage,

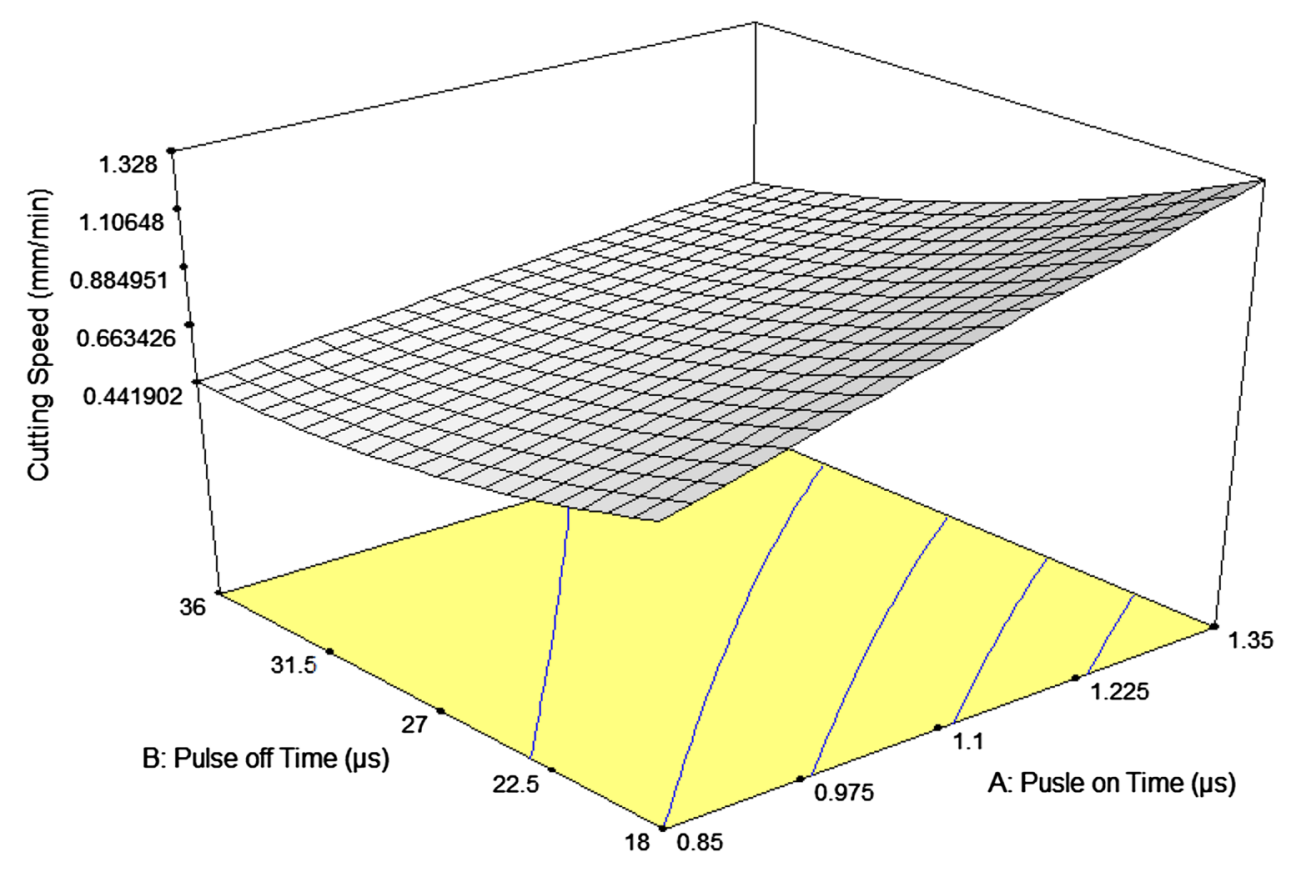

Figure 12. Three-dimensional surface plot between $T_{\text {on }}$ and $T_{\text {off }}$ for cutting speed. 


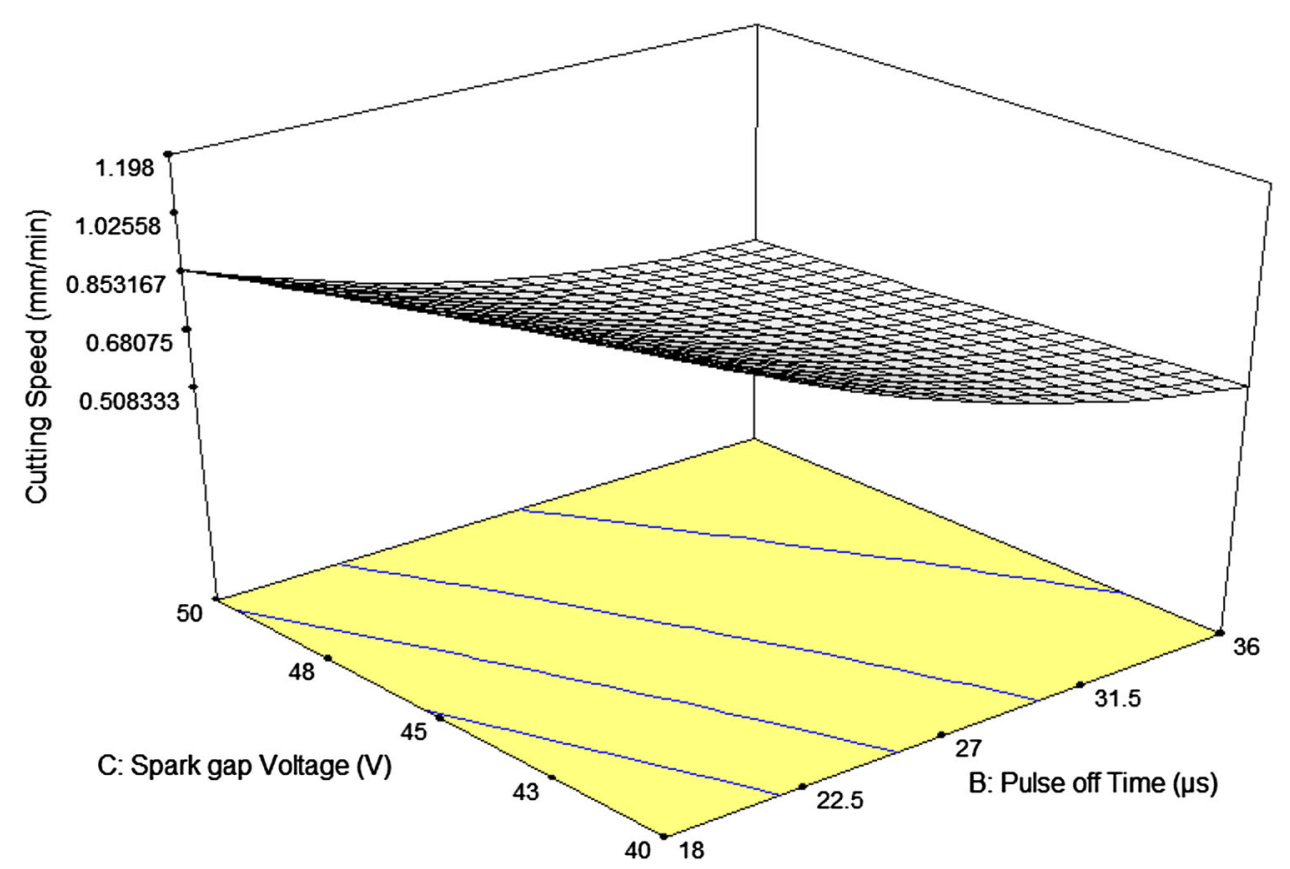

Figure 13. Three-dimensional surface plot between $T_{\text {off }}$ and SV for cutting speed.

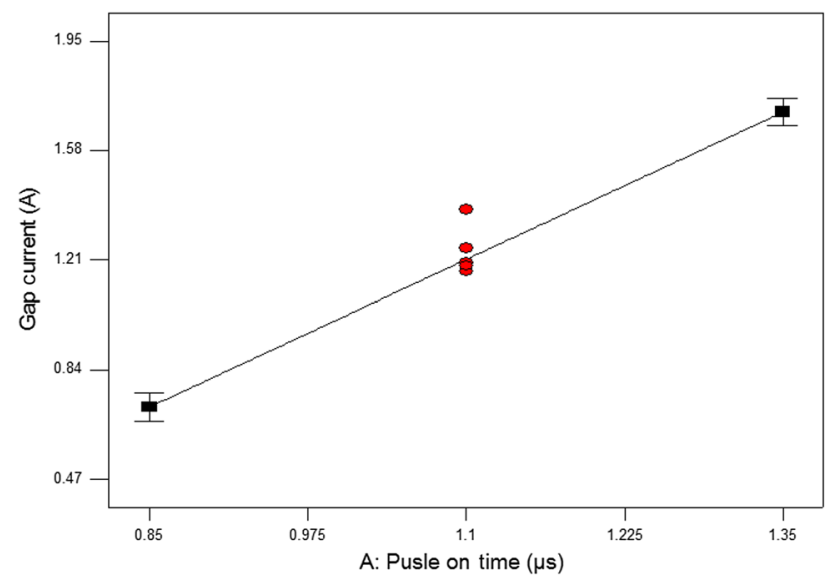

Figure 14. Effect of pulse on time on gap current.

the value of gap current (Ig) decreased instantly. It was observed from figure 15 that the gap current was found to be decreased by $43 \%$ from 1.543 to $0.881 \mathrm{~A}$ with the increase of $T_{\text {off }}$ from 18 to $36 \mu \mathrm{s}$. Figure 16 indicates that gap current (Ig) value was decreased by $18 \%$ from 1.335 to 1.089 A with increase of SV from 40 to $50 \mathrm{~V}$. With the increase of $T_{\mathrm{on}}$, gap current increases. This is because, due to increase in $T_{\mathrm{on}}$, the spark energy is increased to sustain the machining thereby demanding more gap current, which results in increased gap current. The reverse phenomenon takes place with the increase of $T_{\text {off }}$, resulting in reduction of the requirement of gap current. With regard to SV, higher the SV, higher will be the discharge waiting time and lower will be the corresponding demand for gap

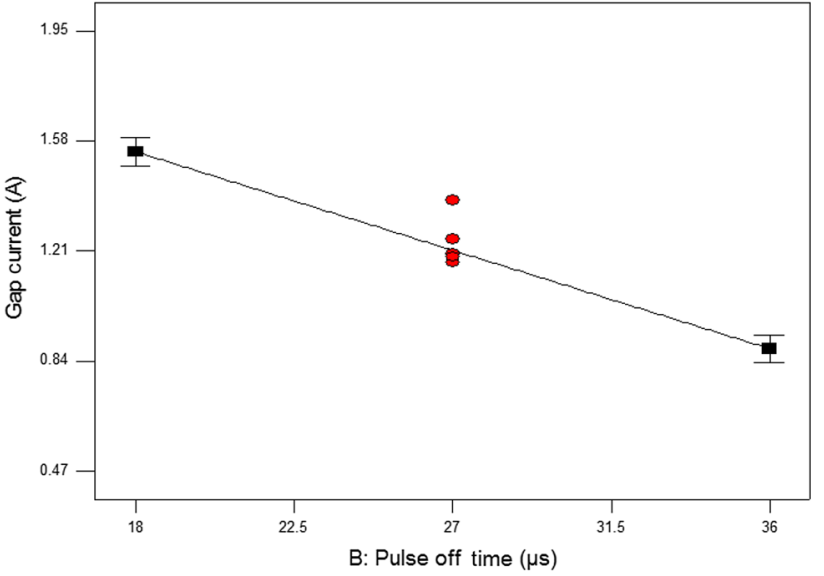

Figure 15. Effect of pulse off time on gap current.

current. So, for minimum gap current, which is the desirability criterion, the setting is $T_{\text {on }}=0.85 \mu \mathrm{s}$. $T_{\text {off }}=36 \mu \mathrm{s}$ and $\mathrm{SV}=50 \mathrm{~V}$. From ANOVA (table 9), it is evident that the effect of parameter wire feed (WF) as a single factor is not significant for the response gap current, although it is involved in two interactions. The percentage contribution of significant process parameters are $T_{\mathrm{on}}=61 \%$, $T_{\text {off }}=27 \%$, and SV $=4 \%$. The "Prob. $>\mathrm{F}$ " value for the two interactions $T_{\text {on }} \times \mathrm{WF}$ and $\mathrm{SV} \times \mathrm{WF}$ are as 0.0001 and 0.0192 , respectively. Then, according to the degree of significance, the interaction $T_{\text {on }} \times \mathrm{WF}$ was discussed according to the interaction plot as observed in figures 17 and 18. It can be observed that the value of gap current (Ig) decreased significantly by $72 \%$ from 1.947 to $0.527 \mathrm{~A}$ 


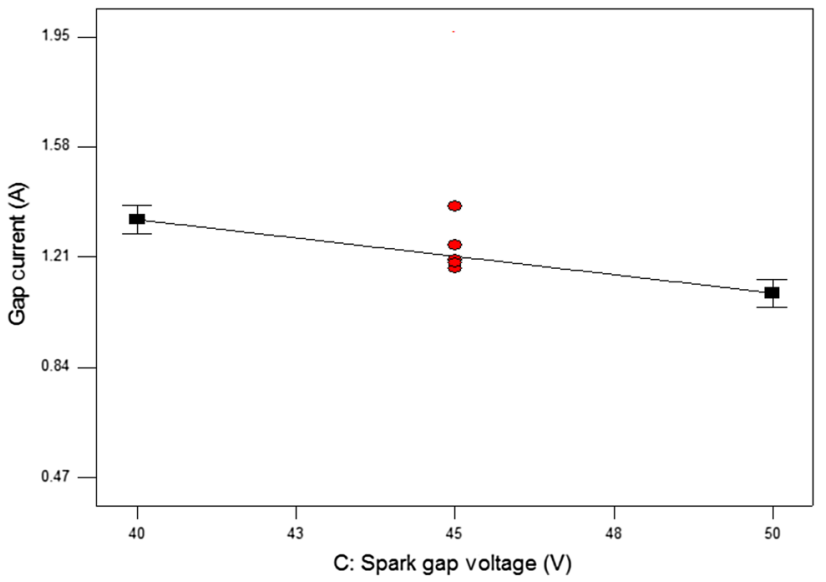

Figure 16. Effect of spark gap voltage on gap current.

when the $T_{\text {on }}$ value was decreased from 1.35 to $0.85 \mu \mathrm{s}$, keeping the wire feed constant at $7 \mathrm{~m} / \mathrm{min}$. Whereas, when the wire feed was kept fixed at $3 \mathrm{~m} / \mathrm{min}$, and the $T_{\text {on }}$ was decreased over the same range as before, the gap current was decreased by $38 \%$ only from 1.472 to 0.902 A. Similar inferences can be drawn from the interaction plot between Ton $\times$ WF. Here, when the WF is kept constant at $7 \mathrm{~m} / \mathrm{min}$ and $\mathrm{SV}$ is increased from 40 to $50 \mathrm{~V}$, the gap current (Ig) decreased by $33 \%$ from 1.478 to $0.996 \mathrm{~A}$. Whereas, at a lower setting of $\mathrm{WF}$ at $3 \mathrm{~mm} / \mathrm{min}$, when $\mathrm{SV}$ was varied from 40 to $50 \mathrm{~V}$, like previously, the gap current value decreased marginally by $1 \%$ from 1.193 to 1.181 A. So, it can be concluded that, although WF as a single factor is insignificant for gap current, its setting at higher value, that is, $7 \mathrm{~m} / \mathrm{min}$ influences the interaction terms significantly. 4.7c Surface roughness $(R a)$ : The main effects plots and interaction plots were considered only for those factors that were found to be significant from ANOVA test (table 11). Three factors such as pulse on time $\left(T_{\text {on }}\right)$, pulse off time $\left(T_{\text {off }}\right)$, spark gap voltage (SV) and three interactions $T_{\text {on }} \times \mathrm{SV}, T_{\text {off }} \times \mathrm{SV}$ and $T_{\text {off }} \times \mathrm{WF}$ were significant for surface roughness. Main effect plots of $T_{\text {on }}, T_{\text {off }}, \mathrm{SV}$ for surface roughness are shown in figures 19, 20 and 21 . The interaction graphs of $T_{\text {off }} \times \mathrm{WF}, T_{\text {off }} \times \mathrm{SV}$ and $T_{\text {on }} \times \mathrm{SV}$ are shown in figures $22-24$. When pulse on time $\left(T_{\text {on }}\right)$ was increased from 0.85 to $1.35 \mu \mathrm{s}$, the surface roughness increased significantly from 1.908 to $3.168 \mu \mathrm{m}$ (i.e. $66 \%$ ) as observed in figure 19. This increment of surface roughness may be attributed to the following reason. Larger $T_{\text {on }}$ increases the discharge energy to the work piece surface. This leads to the generation of rough surface due to formation of deeper and irregular craters by occurrence of violent sparks and melting of excess amount of the work piece material in the machining zone and improper flushing of this excess amount of molten material [26]. When pulse off time ( $\left.T_{\text {off }}\right)$ increases, the opposite phenomenon occurs. As can be noticed from figure 20, a fall in the value of surface roughness was observed from 2.782 to $2.294 \mu \mathrm{m}(\sim 18 \%)$ by increasing the value of pulse off time from 18 to $36 \mu$ s to give a finer surface. So, it is observed that $T_{\text {off }}$ bears an inverse relationship with surface roughness. Due to increase in surface roughness with lower $T_{\text {off }}$ and lower wire feed may result in poor flushing of molten material from the machining zone and short-circuiting of wire electrode due to the presence of the residual or unexpelled molten material in the inter-electrode gap. The effect of spark gap voltage (SV) on surface roughness can be observed in figure 21 that when SV

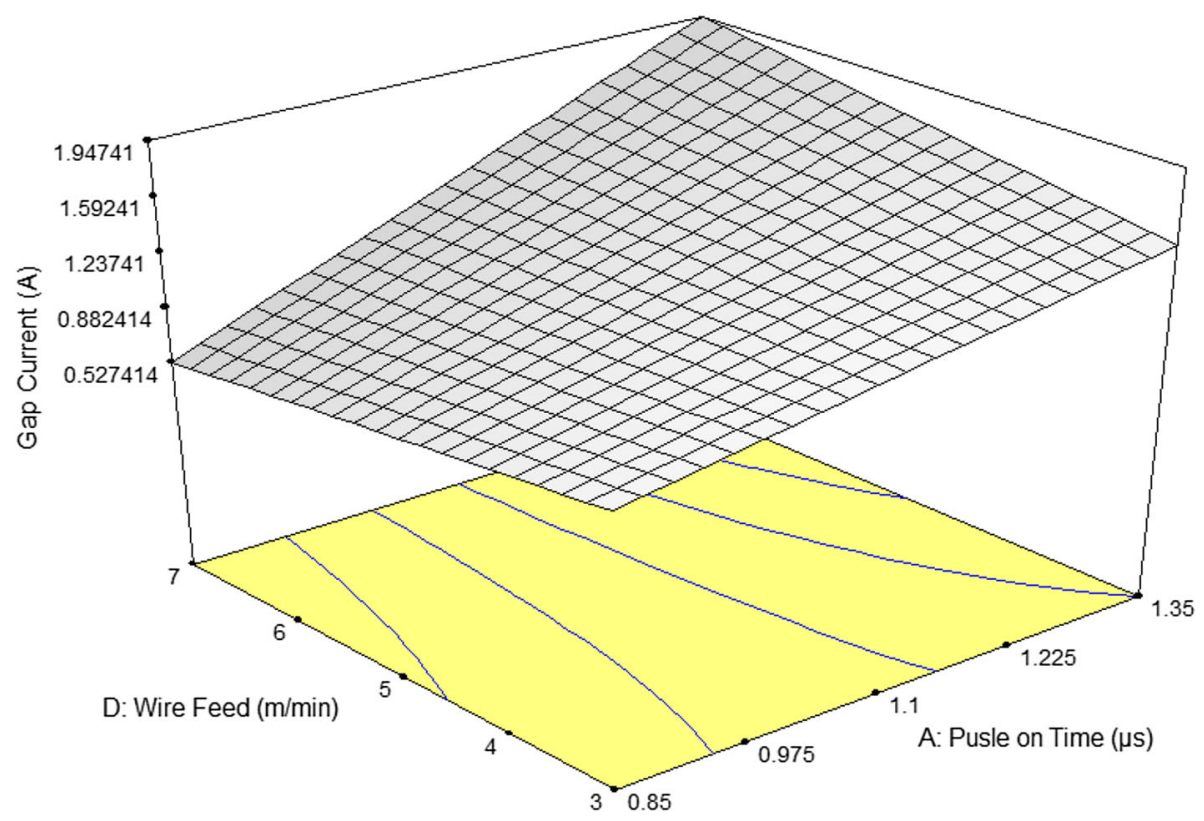

Figure 17. Three-dimensional surface plot between $T_{\mathrm{on}}$ and WF for gap current. 


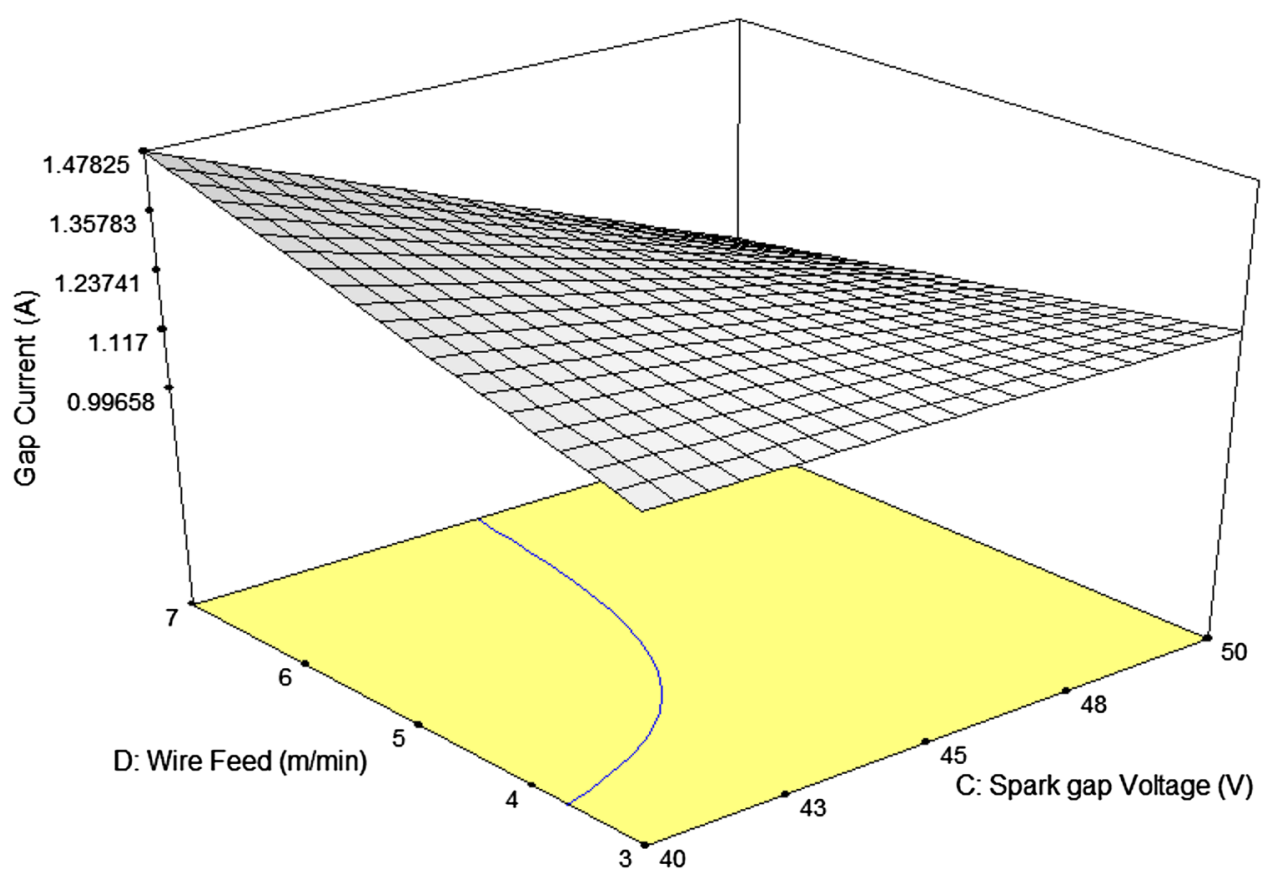

Figure 18. Three-dimensional surface plot between SV and WF for gap current.

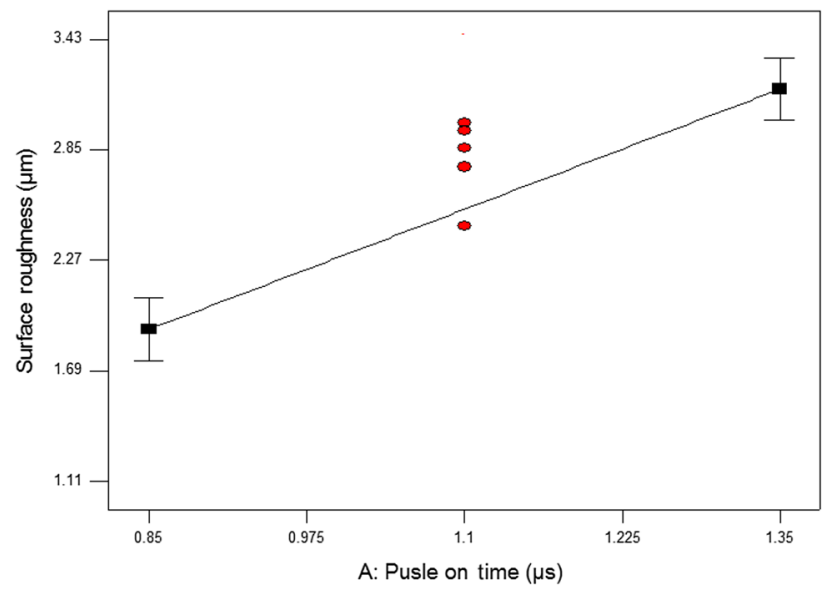

Figure 19. Effect of pulse on time on surface roughness.

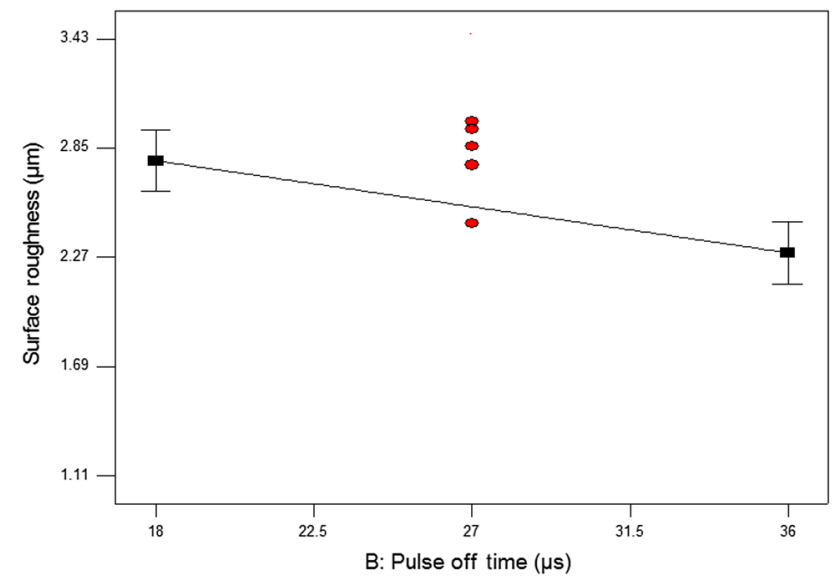

Figure 20. Effect of pulse off time on surface roughness.

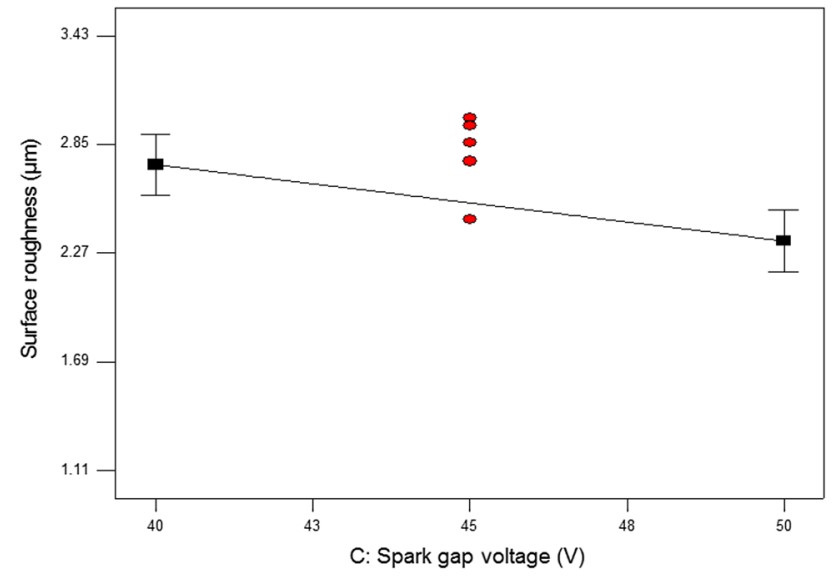

Figure 21. Effect of spark gap voltage on surface roughness.

is increased from 40 to $50 \mathrm{~V}$, the surface roughness decreases from 2.741 to $2.334 \mu \mathrm{m}$. This decrement of $15 \%$ is showing approximate trends in line with the effect of $T_{\text {off }}$. Like $T_{\text {off }}$, SV also shows an inverse relationship with surface roughness values. The above trend is due to the fact that, with higher $T_{\text {off }}$ and $\mathrm{SV}$, the discharge waiting time becomes longer and the work piece and wire electrode gap becomes wider, which promotes proper flushing of the machining zone and ultimately a stable cut. This helps in improving the surface roughness, that is, decreases in surface roughness value. Also from ANOVA, the percentage contribution of $T_{\text {on }}$ was $46 \%, T_{\text {off }}=7 \%$, and that of $\mathrm{SV}=5 \%$. Next, the interactions affecting the surface roughness discussed as per the degree of their significance (the "Prob. $>$ F" value bearing the least value is the most significant). The interaction graph of $T_{\text {off }} \times \mathrm{WF}$ for surface roughness is shown in 


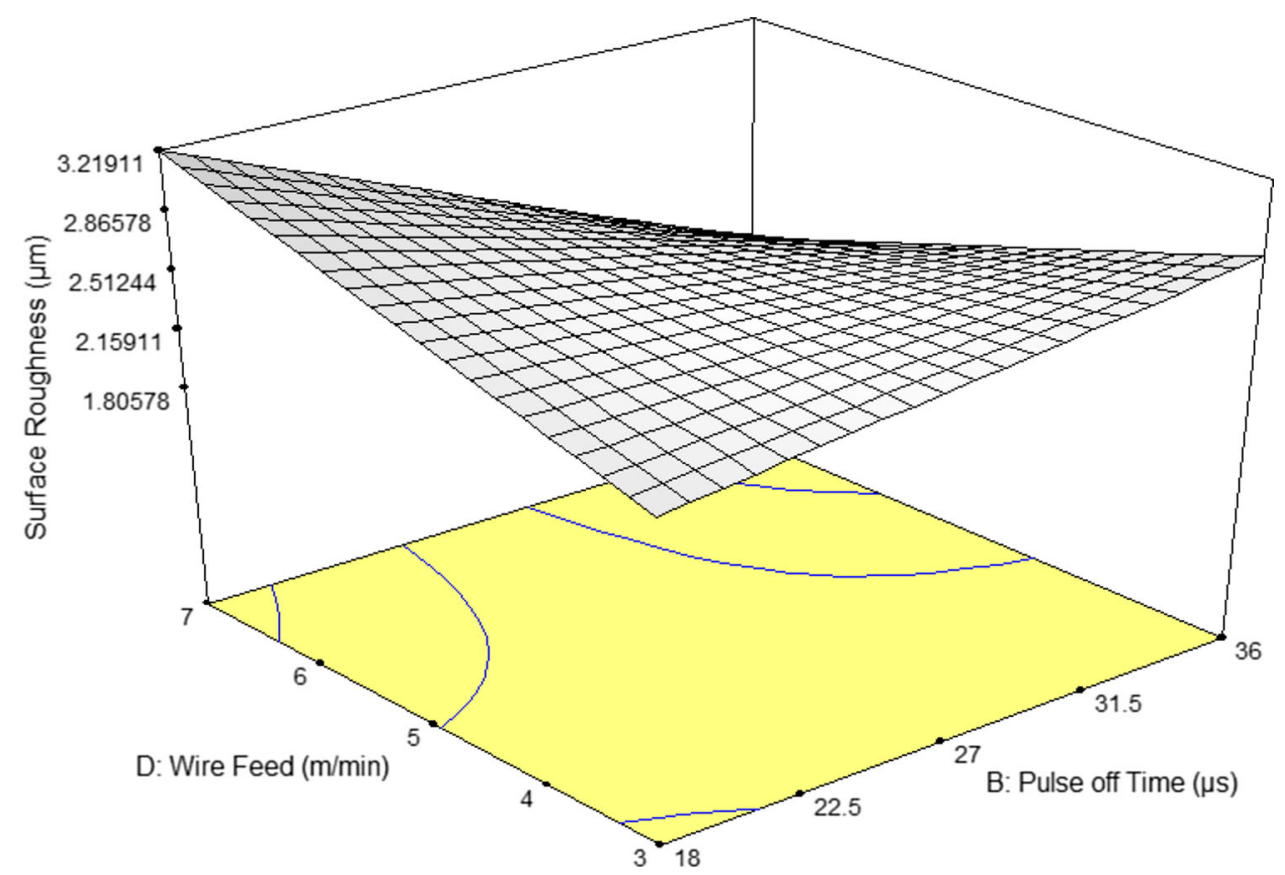

Figure 22. Three-dimensional surface plot between $T_{\text {off }}$ and WF for surface roughness.

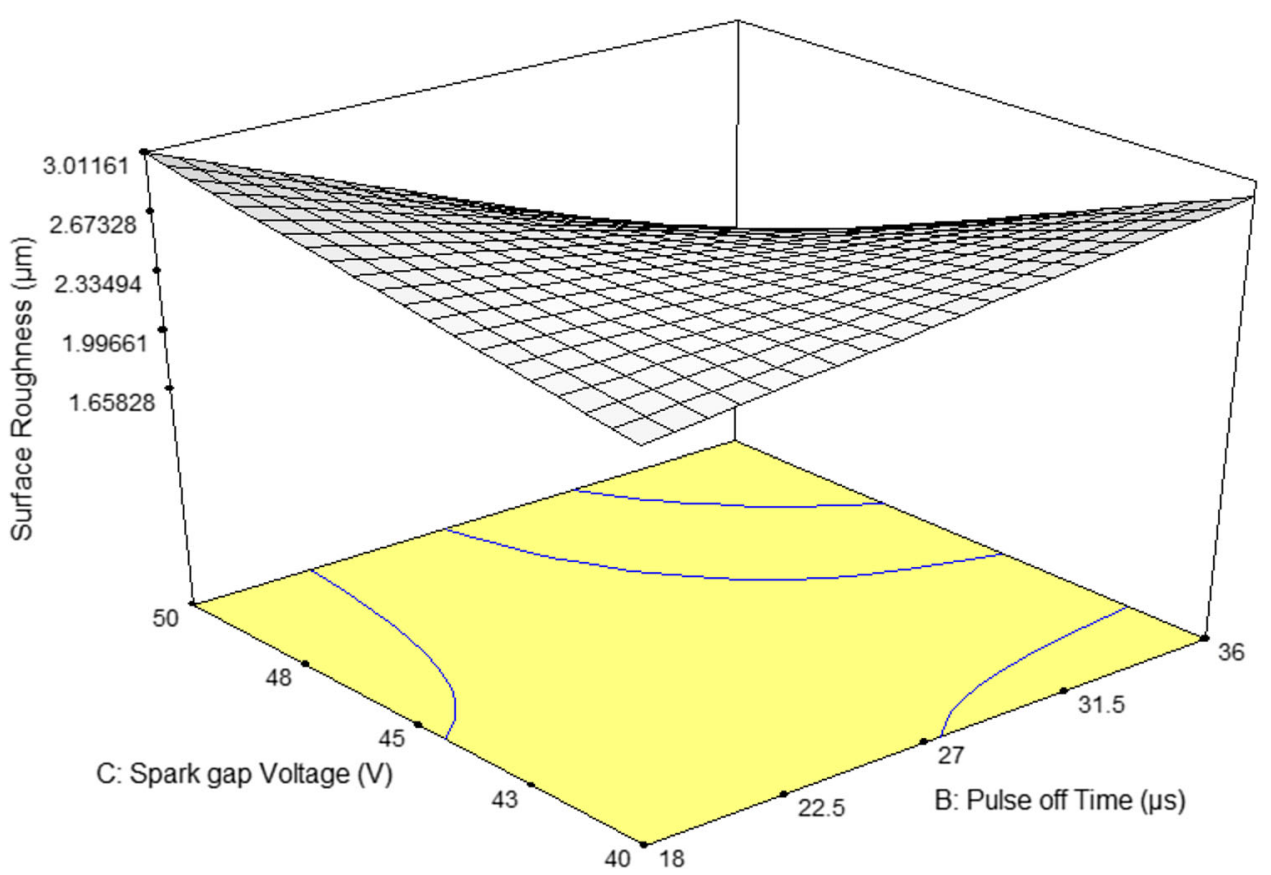

Figure 23. Three-dimensional surface plot between $\mathrm{SV}$ and $T_{\text {off }}$ for surface roughness.

figure 22. From this interaction plot, when $T_{\text {off }}$ is increased from 18 to $36 \mu \mathrm{s}$, keeping wire feed at $3 \mathrm{~m} / \mathrm{min}$, the surface roughness was noticed to increase from 2.345 to $2.782 \mu \mathrm{m}$ (i.e. an increment of $18.63 \%$ ). Also, when $T_{\text {off }}$ was varied by the same amount as before, with WF set at $7 \mathrm{~m} / \mathrm{min}$, a significant decrement from 3.219 to $1.805 \mu \mathrm{m}$ in surface roughness was observed. The percentage decrement in the value of surface roughness was recorded $44 \%$ as WF was set at $7 \mathrm{~m} / \mathrm{min}$. Hence, it is evident that although WF as a single factor has no direct impact on surface roughness, it had considerable impact when involved with an interaction with $T_{\text {off }}$ at a higher setting of $7 \mathrm{~m} / \mathrm{min}$. So, to gain minimum 
surface roughness, the parameters of $T_{\text {off }}$ and WF should be set at $36 \mu \mathrm{s}$ and $7 \mathrm{~m} / \mathrm{min}$, respectively. The next dominant interaction on surface roughness is the interaction between $T_{\text {off }}$ and SV. The interaction graph is shown in figure 23. It can be seen in this interaction plot that, keeping SV at $40 \mathrm{~V}$, when $T_{\text {off }}$ was increased from 18 to $36 \mu \mathrm{s}$, the surface roughness showed an increment of $15 \%$, from 2.553 to $2.929 \mu \mathrm{m}$. Whereas setting the value at $50 \mathrm{~V}$, when $T_{\text {off }}$ was varied by the same range as earlier, the surface roughness recorded a significant decrement at $45 \%$ from 3.011 to $1.658 \mu \mathrm{m}$. This implies that for a fine surface we need to set $T_{\text {off }}$ and SV at $36 \mu$ s and $50 \mathrm{~V}$, respectively. Figure 24 shows the interaction graph of $T_{\text {on }}$ and $\mathrm{SV}$ for surface roughness. When $\mathrm{SV}$ was set fixed at $40 \mathrm{~V}$, with increase of $T_{\text {on }}$ from 0.85 to $1.35 \mu \mathrm{s}$, the surface roughness was found to increase dramatically by $111 \%$ from 1.764 to $3.719 \mu \mathrm{m}$; whereas, for higher setting of SV at $50 \mathrm{~V}$, with the same variation of $T_{\text {on }}$ as earlier, the increment in surface roughness was recorded $28 \%$ from 2.052 to $2.617 \mu \mathrm{m}$. This indicates that, to obtain minimum surface roughness, the setting for $T_{\text {on }}$ and $\mathrm{SV}$ should be $0.85 \mu$ s and $50 \mathrm{~V}$, respectively.

\section{Multi-response optimization through desirability function}

Multi-response optimization is a process of maintaining a balance between two or more than two responses. From productivity, surface quality, and cost/ power consumption point of view, we often encounter response characteristics which are conflicting in nature, for example, when cutting speed increases, surface finish decreases and gap current increases. Therefore, there is hardly any possibility of having a single optimal setting for all three responses. However, it is possible to consider the multi-response optimization problem into a single response problem by measurement of mathematical transformations. Deringer and Suich [25] presented a multi-response technique called desirability. It is very useful for optimization of multiple quality characteristics problem encountered during research work and for industry. This method is credited to be intuitive and simple and hence used widely. The inputs are mean response estimates, target value, and upper and lower acceptability bounds. The individual desirability is combined using the geometric mean. The desirability of a product characteristics value depends on the lower and upper ranges of product specification. Improper selection of ranges may result in a very different "optimum." The desirability function involves transformation of each estimated response variable $\hat{y}$ to a desirability value $d i$, where $0 \leq d i \leq 1$. The value of $d i$ increases as the "desirability" of the corresponding response increases. The procedure followed in this work for simultaneous optimization of the three responses as follows:
Step 1 Calculate the individual desirability (di) for each response $(\hat{y})$.

Step 2 Combine individual desirability to obtain composite desirability (DG) for given weights of cutting speed, gap current, and surface roughness. Composite desirability is the weighted geometric mean of individual desirability for the given responses.

Step 3 Maximize the composite desirability and identifying the optimal parameter combinations.

$$
d i=\left\{\begin{array}{c}
0 \hat{\mathrm{y}}<A i \\
(\hat{\mathrm{y}}-A i / t i-A i)^{\mathrm{w}} A i \leq \hat{\mathrm{y}} \leq t i \\
1 \hat{\mathrm{y}}>t i
\end{array}\right.
$$

If the target $(t i)$ is to minimize a response, the individual desirability $(d i)$ is calculated as

$$
d i=\left\{\begin{array}{c}
1 \hat{\mathrm{y}}<t i \\
(B i-\hat{\mathrm{y}} / B i-t i)^{\mathrm{w}} t i \leq \hat{\mathrm{y}} \leq B i \\
0 \hat{\mathrm{y}}>B i
\end{array}\right.
$$

where

$A i$ is the lower limit value of response $\hat{y}$ and $B i$ is the upper limit value of response $\hat{y}$.

If the object for the response is a target value, then individual desirability $(d i)$ is calculated as

$$
\begin{aligned}
& d i=[(\hat{y}-A i) /(t i-A i)]^{w} \quad L i \leq \hat{y} \leq t i \\
& d i=[(B i-\hat{y}) /(B i-t i)]^{w} \quad t i \leq \hat{y} \leq B i \\
& d i=0 \text { if } \hat{y} A i \\
& d i=0 \text { if } \hat{y} B i
\end{aligned}
$$

If the importance is same for each response, the composite desirability (DG) is the geometric mean of all desirability functions and is given by

$$
\mathrm{DG}=\left(d_{1} \times d_{2} \times d_{3} \times \cdots \times d_{n}\right)^{1 / n}=\left(\prod_{i=1}^{n} d i\right)^{1 / n}
$$

Where $n=$ no. of responses $=3$

It can be extensive to reflect on the possible difference in the importance of different responses by giving weights. Where the weight wi satisfies $0<w i<1$ and $w_{1}+w_{2}+\cdots+w_{n}=1$

$$
\mathrm{DG}=\left(d_{1}^{\mathrm{w} 1} \times d_{2}^{\mathrm{w} 2} \times \cdots d_{n}^{\mathrm{wn}}\right)^{1 / n}
$$

The factor settings with maximum total desirability are considered to be optimal parameter combination. In the present work, desirability function is utilized to determine the optimum parameter combinations for optimization of cutting speed (CS), gap current (Ig), and surface roughness (Ra).

Table 12 illustrates the constraints for carrying out optimization of responses, that is, cutting speed (CS), gap 


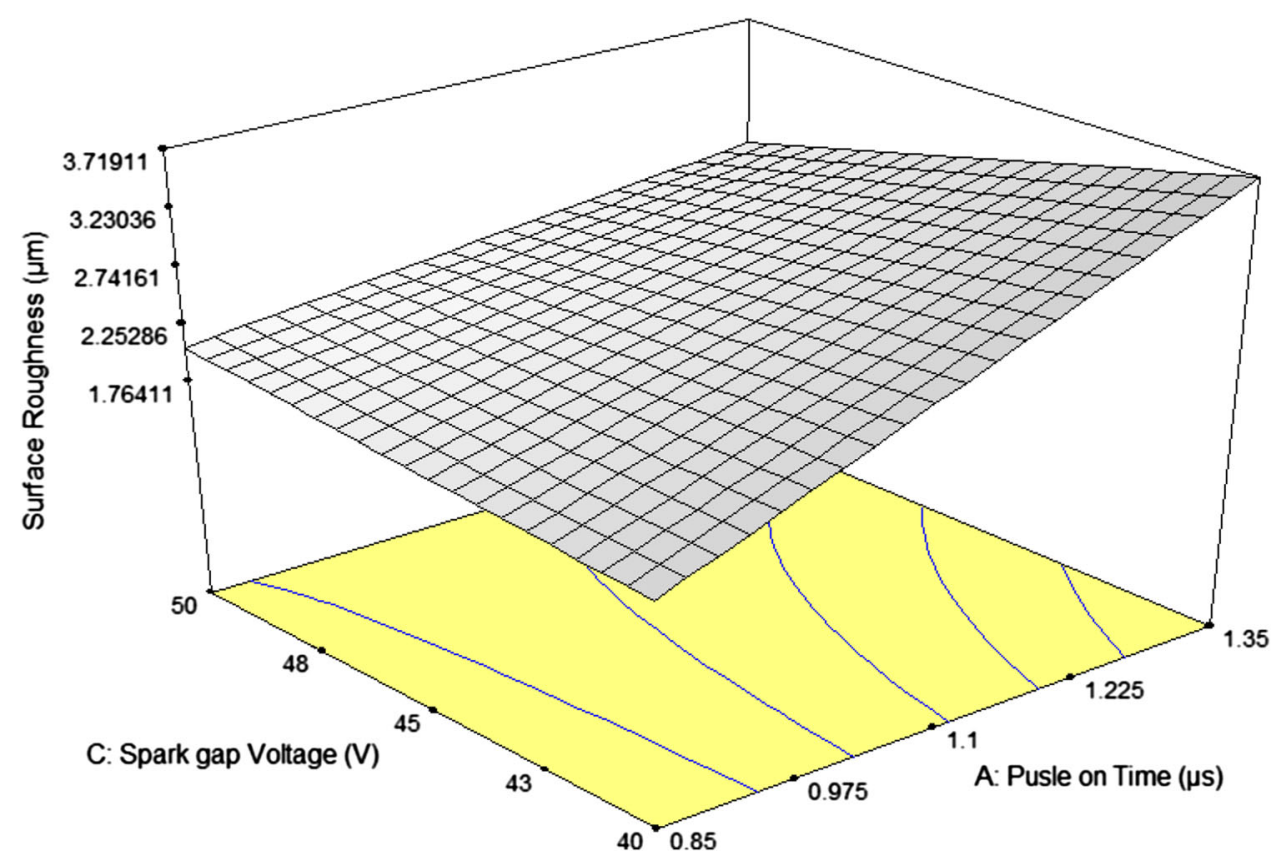

Figure 24. Three-dimensional surface plot between $T_{\text {on }}$ and $\mathrm{SV}$ for surface roughness.

current (Ig), and surface roughness (Ra). Goals to maximize, minimize, or to keep the response at a target value and limits for control factors are established for each response individually in order to accurately determine their impact on individual desirability. Weights are assigned to give added emphasis to upper/lower bounds or to emphasize a target value. The default value ' 1 ' of weight is assigned to a goal to adjust the shape of its particular desirability function. Equal weights of different objective functions/performance measures assign equal importance to all the objective functions because the ultimate objective of optimization is to find a set of conditions that will meet all the goals. Equal importance is provided to all the responses to avoid the use of any further finishing cut to improve the surface roughness. If more importance is given to productivity aspect, that is, cutting speed or gap current, surface obtained will be rough. If higher importance is given to surface roughness, machines need to be run at a very low cutting speed as revealed by the analysis. This will affect the overall economy of the production operation. It is not necessary that the value of desirability is always 1.0 as this value is completely dependent on the manner in which lower and upper limits are set relative to the actual optimum. The data used for carrying out multi-objective optimization of cutting speed (CS), gap current (Ig), and surface roughness (Ra) using design expert ${ }^{\circledR}$ are presented in table 5. It shows 24 optimal solutions. Table 13 shows the values of 24-level combinations of process parameters that will give high value of composite desirability (ranged from 0.630 to 0.372 ) and the predicted values of responses obtained are also given. Figures 25, 26 and 27 shows the three-dimensional response surface, optimized bar histograms, and ramp graphs for overall desirability of all three responses,

Table 12. Constraints of input parameters and responses.

\begin{tabular}{|c|c|c|c|c|c|c|}
\hline Parameters & Goal & Lower limit & Upper limit & Lower weight & Upper weight & Importance \\
\hline \multicolumn{7}{|l|}{ Inputs } \\
\hline$T_{\text {on }}$ & In range & 0.85 & 1.35 & 1 & 1 & 3 \\
\hline$T_{\text {off }}$ & In range & 18 & 36 & 1 & 1 & 3 \\
\hline SV & In range & 40 & 50 & 1 & 1 & 3 \\
\hline WF & In range & 3 & 7 & 1 & 1 & 3 \\
\hline \multicolumn{7}{|l|}{ Responses } \\
\hline Cutting speed & Maximize & 0.44 & 1.27 & 1 & 1 & 5 \\
\hline Gap current & Minimize & 0.47 & 1.95 & 1 & 1 & 3 \\
\hline Surface roughness & Minimize & 1.11 & 3.43 & 1 & 1 & 3 \\
\hline
\end{tabular}


Table 13. Optimal solutions for cutting speed, gap current and surface roughness.

\begin{tabular}{|c|c|c|c|c|c|c|c|c|}
\hline $\begin{array}{l}\text { Soln. } \\
\text { no. }\end{array}$ & $\begin{array}{l}T_{\text {on }} \\
(\mu \mathrm{s})\end{array}$ & $\begin{array}{l}T_{\text {off }} \\
(\mu \mathrm{s})\end{array}$ & $\begin{array}{l}\text { SV } \\
(\mathrm{V})\end{array}$ & $\begin{array}{l}\mathrm{WF}(\mathrm{m} / \\
\min )\end{array}$ & $\begin{array}{l}\text { Cutting speed CS }(\mathrm{mm} / \\
\min )\end{array}$ & $\begin{array}{l}\text { Gap current Ig } \\
\text { (A) }\end{array}$ & $\begin{array}{l}\text { Surface roughness } \\
\qquad(\mu \mathrm{m})\end{array}$ & Desirability \\
\hline 1 & 0.90 & 18 & 40 & 3 & 0.967 & 1.30 & 1.35 & 0.630 \\
\hline 2 & 0.89 & 18 & 40 & 3 & 0.952 & 1.28 & 1.30 & 0.630 \\
\hline 3 & 0.90 & 18.02 & 40.01 & 3 & 0.968 & 1.30 & 1.36 & 0.629 \\
\hline 4 & 0.91 & 18 & 40 & 3.13 & 0.977 & 1.31 & 1.41 & 0.628 \\
\hline 5 & 0.85 & 18 & 40 & 3 & 0.907 & 1.24 & 1.15 & 0.626 \\
\hline 6 & 0.85 & 18 & 40 & 3.36 & 0.903 & 1.22 & 1.21 & 0.622 \\
\hline 7 & 0.87 & 18 & 40 & 3.57 & 0.933 & 1.25 & 1.36 & 0.622 \\
\hline 8 & 0.88 & 18 & 40 & 3.62 & 0.943 & 1.26 & 1.41 & 0.621 \\
\hline 9 & 0.98 & 18 & 40 & 3.10 & 1.063 & 1.39 & 1.69 & 0.620 \\
\hline 10 & 0.88 & 18 & 40 & 3.75 & 0.948 & 1.26 & 1.43 & 0.620 \\
\hline 11 & 0.99 & 18.36 & 40 & 3 & 1.053 & 1.38 & 1.72 & 0.615 \\
\hline 12 & 1.03 & 18 & 40 & 3 & 1.117 & 1.45 & 1.85 & 0.612 \\
\hline 13 & 0.85 & 18 & 40 & 4.74 & 0.905 & 1.18 & 1.52 & 0.609 \\
\hline 14 & 1.05 & 18 & 40 & 3 & 1.140 & 1.47 & 1.94 & 0.604 \\
\hline 15 & 0.85 & 18 & 40 & 5.49 & 0.903 & 1.15 & 1.68 & 0.599 \\
\hline 16 & 0.85 & 18 & 40 & 5.58 & 0.903 & 1.15 & 1.70 & 0.598 \\
\hline 17 & 0.85 & 18 & 40 & 5.78 & 0.903 & 1.14 & 1.74 & 0.595 \\
\hline 18 & 0.85 & 18 & 40 & 6.2 & 0.903 & 1.12 & 1.84 & 0.589 \\
\hline 19 & 0.85 & 18.16 & 40 & 6.1 & 0.896 & 1.12 & 1.81 & 0.588 \\
\hline 20 & 0.97 & 18 & 41.71 & 3 & 0.991 & 1.37 & 1.75 & 0.586 \\
\hline 21 & 1.04 & 20.7 & 40 & 3.03 & 1.009 & 1.36 & 2.11 & 0.560 \\
\hline 22 & 1.09 & 18 & 44.15 & 3 & 1.055 & 1.51 & 2.29 & 0.514 \\
\hline 23 & 1.24 & 22.66 & 48.02 & 3 & 0.911 & 1.51 & 2.71 & 0.402 \\
\hline 24 & 1.26 & 31.15 & 50 & 7 & 0.696 & 1.31 & 1.97 & 0.372 \\
\hline
\end{tabular}

that is, cutting speed (CS), gap current (Ig), and surface roughness (Ra).

\subsection{Confirmation test}

In the present work, solution no. 1, as suggested by table 13, was used as the basis of the confirmatory experiment. The experiment was carried out using the control factors for optimal solutions and the output responses (cutting speed, gap current, and surface roughness) were listed in table 14.

\subsection{Validation of mathematical models}

The confirmation test was performed to measure the reliability of the optimization results obtained from the analysis. The mathematical models for all three responses were tested against the optimal set of test data to check their predictive performances. The comparison of test results between the experimental values and predicted values was the final consideration to determine whether the optimal parameters predicted were in the allowable range. The margin of error for the prediction and experimental results was set below $10 \%$. The prediction error obtained in table 15 is calculated as
Error $\%=\left|\frac{\text { Experimental value }- \text { Predicted value }}{\text { Experimental value }}\right| \times 100$

The comparison of experimental test results with the predicted results shows that the margin of error obtained was $<10 \%$. It can be observed that the calculated error for cutting speed (CS) and gap current (Ig) was $<3 \%$, which confirms excellent reproducibility of the results for both these responses. Also, the error obtained for the response, surface roughness $(\mathrm{Ra})$ was $<10 \%$, indicating the prediction performance of the model to be quite satisfactory. This proves the validity of the developed mathematical models for cutting speed (CS), gap current (Ig), and surface roughness (Ra).

\section{Surface topography}

Optical micrographs revealed that the surfaces have a complex appearance with shallow craters, spherical particles, melt drops and globules of debris, due to the high heat energy released by discharges and subsequently cooling (figure 28). The spherical particles are molten metal that are expelled randomly during the discharge and then solidified and attached to the surface. The pulse on time 


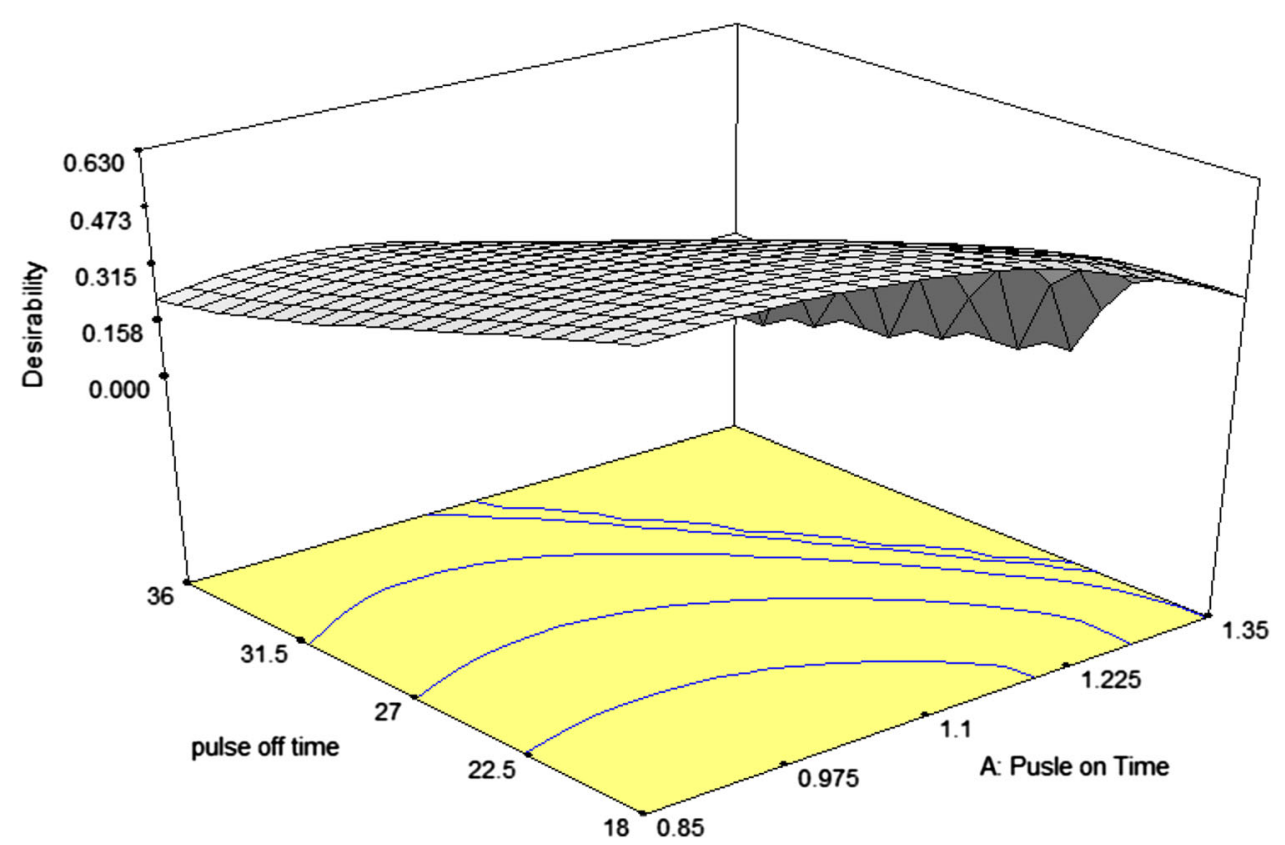

Figure 25. Three-dimensional surface plot of composite desirability for all responses.

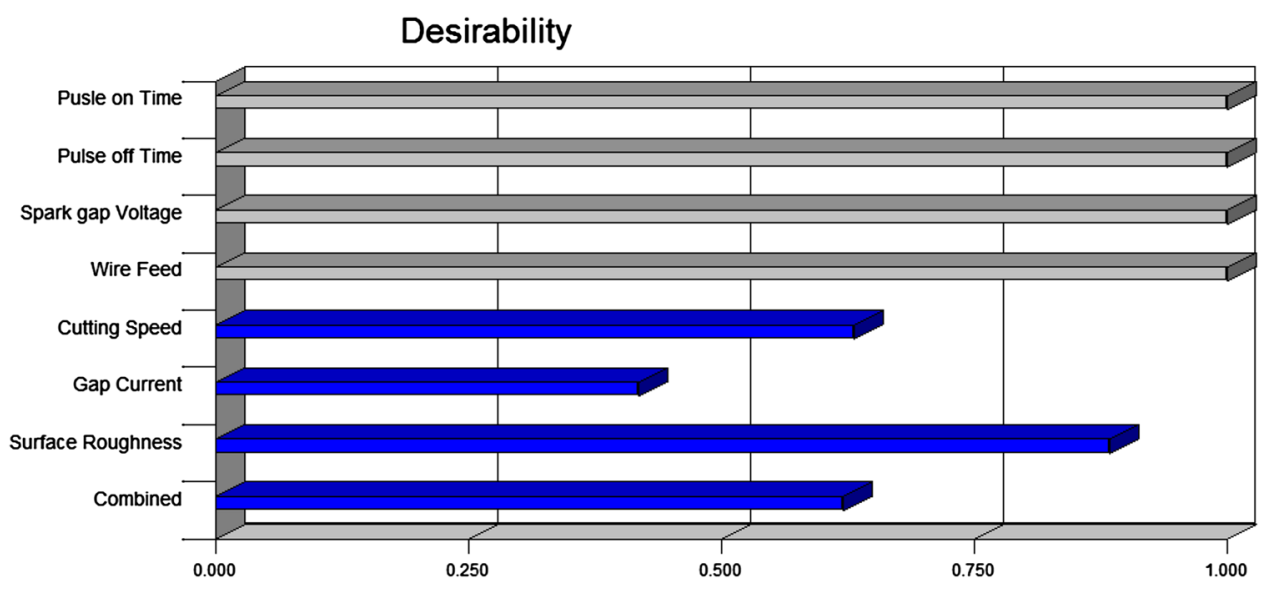

Figure 26. Bar histogram plot of composite desirability for all responses.

$(1.35 \mu \mathrm{s})$ and pulse off time (18 $\mu \mathrm{s})$ were observed as the most significant parameters affecting the surface properties. When pulse on time was increased, the surface texture of the machined surface contains deep crater rims of varying sizes. It was observed that under low pulse off time $(18 \mu \mathrm{s})$ may result in electrical sparks that generate smaller crater rims on the work surface. The recast layer thickness was changed due to superficial hardening of the work material by the discharge heat of electrical spark. The intensity of spark depends on peak current, pulse on time, and pulse off time. The thickness of recast layer of WEDM surface was increased due to increase of pulse on time and decrease of pulse off time as observed in figure 29.

\section{Conclusions}

Based on the performance of WEDM operations of Inconel 625, the following conclusions are drawn between the process parameters and the response characteristics. 


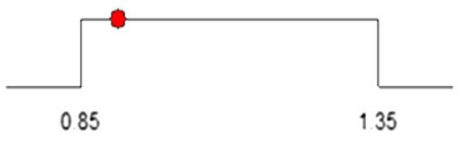

Pusle on Time $=0.915224$

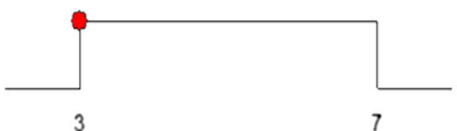

Wire Feed $=3$

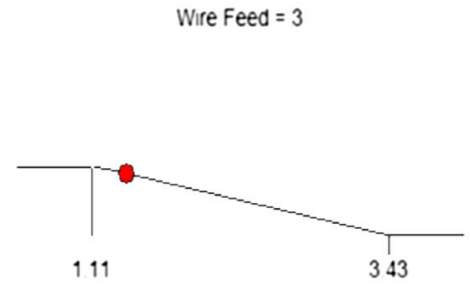

Surface Roughness $=139439$

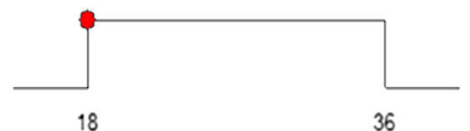

Pulse off Time $=180035$

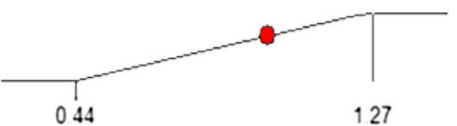

Cutting Speed $=0.97981$

Desirability $=0.630$

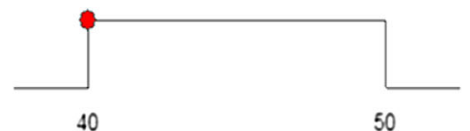

Spark gap Voltage $=40$

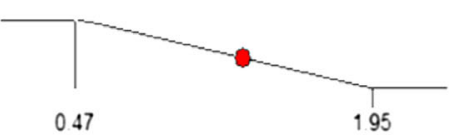

Gap Current $=1.31331$

Figure 27. Ramp graph of optimal setting for all responses.

Table 14. Confirmation test results with optimal parameters setting.

\begin{tabular}{lcccc}
\hline & \multicolumn{4}{c}{ Confirmation test result (responses) } \\
\cline { 2 - 5 } $\begin{array}{l}\text { Optimal control } \\
\text { parameters }\end{array}$ & Reading & $\begin{array}{c}\mathrm{CS}(\mathrm{mm} / \\
\mathrm{min})\end{array}$ & $\begin{array}{c}\mathrm{Ig} \\
(\mathrm{A})\end{array}$ & $\begin{array}{c}\mathrm{Ra} \\
(\mu \mathrm{m})\end{array}$ \\
\hline$T_{\text {on }}=0.9 \mu \mathrm{s}$ & 1 & 0.98 & 1.4 & 1.42 \\
$T_{\text {off }}=18 \mu \mathrm{s}$ & 2 & 1.00 & 1.3 & 1.34 \\
$\mathrm{SV}=40 \mathrm{~V}$ & 3 & 0.97 & 1.2 & 1.71 \\
$\mathrm{WF}=3 \mathrm{~m} / \mathrm{min}$ & Average & 0.9925 & 1.325 & 1.49 \\
\hline
\end{tabular}

Table 15. Validation of mathematical models with experimental data.

\begin{tabular}{lccc}
\hline Responses & Experimental & Predicted & Error $(\%)$ \\
\hline $\mathrm{CS}(\mathrm{mm} / \mathrm{min})$ & 0.9925 & 0.967 & 2.56 \\
$\mathrm{Ig}(\mathrm{A})$ & 1.325 & 1.30 & 1.88 \\
$\operatorname{Ra}(\mu \mathrm{m})$ & 1.49 & 1.35 & 9.39 \\
\hline
\end{tabular}

1. Cutting speed increased significantly from 0.505 to $0.915 \mathrm{~mm} / \mathrm{min}(81 \%)$ as $T_{\text {on }}$ was increased from 0.85 to $1.35 \mu$ s. Cutting speed increased significantly from 0.558 to $1.033 \mathrm{~mm} / \mathrm{min}(85 \%)$ as $T_{\text {off }}$ was decreased from 36 to $18 \mu \mathrm{s}$. Also, cutting speed increased marginally from 0.608 to $0.818 \mathrm{~mm} / \mathrm{min}(36 \%)$ as SV decreased from 50 to $40 \mathrm{~V}$. The maximum cutting speed obtained in this research was $1.27 \mathrm{~mm} / \mathrm{min}$ with input settings of $T_{\text {on }}=1.35 \mu \mathrm{s}, \quad T_{\text {off }}=18 \mu \mathrm{s}, \quad \mathrm{SV}=45 \mathrm{~V}, \quad$ and $\mathrm{WF}=5 \mathrm{~m} / \mathrm{min}$.

2. The gap current (Ig) is mainly affected by pulse on time $\left(T_{\text {on }}\right)$, pulse off time $\left(T_{\text {off }}\right)$, and spark gap voltage $(\mathrm{SV})$. Ig is ranged between 0.47 and $1.95 \mathrm{~A}$. $T_{\mathrm{on}}$ is the most significant and dominant factor with $60.61 \%$ contribution as compared to $T_{\text {off }}$ and $\mathrm{SV}$. The percentage contribution of $T_{\text {off }}$ and SV are $26.73 \%$ and $3.67 \%$, respectively.

3. The surface roughness $(\mathrm{Ra})$ is mainly affected by on time $\left(T_{\text {on }}\right)$, pulse off time $\left(T_{\text {off }}\right)$, and spark gap voltage (SV). The value of surface roughness obtained in this research work was ranged between 1.11 and $3.43 \mu \mathrm{m}$. For surface roughness, the most significant and dominant factor is $T_{\text {on }}$ with $46.34 \%$ contribution. The percentage contributions of $T_{\text {off }}$ and SV for $\mathrm{Ra}$ are $7.01 \%$ and $4.86 \%$, respectively.

4. It was observed that pulse on time and pulse off time deteriorate the integrity of machined samples, which produces deeper and wider overlapping craters and globules of debris.

5. Recast layer thickness is mostly influenced by pulse on time; and pulse off time is found to be relatively most significant. 


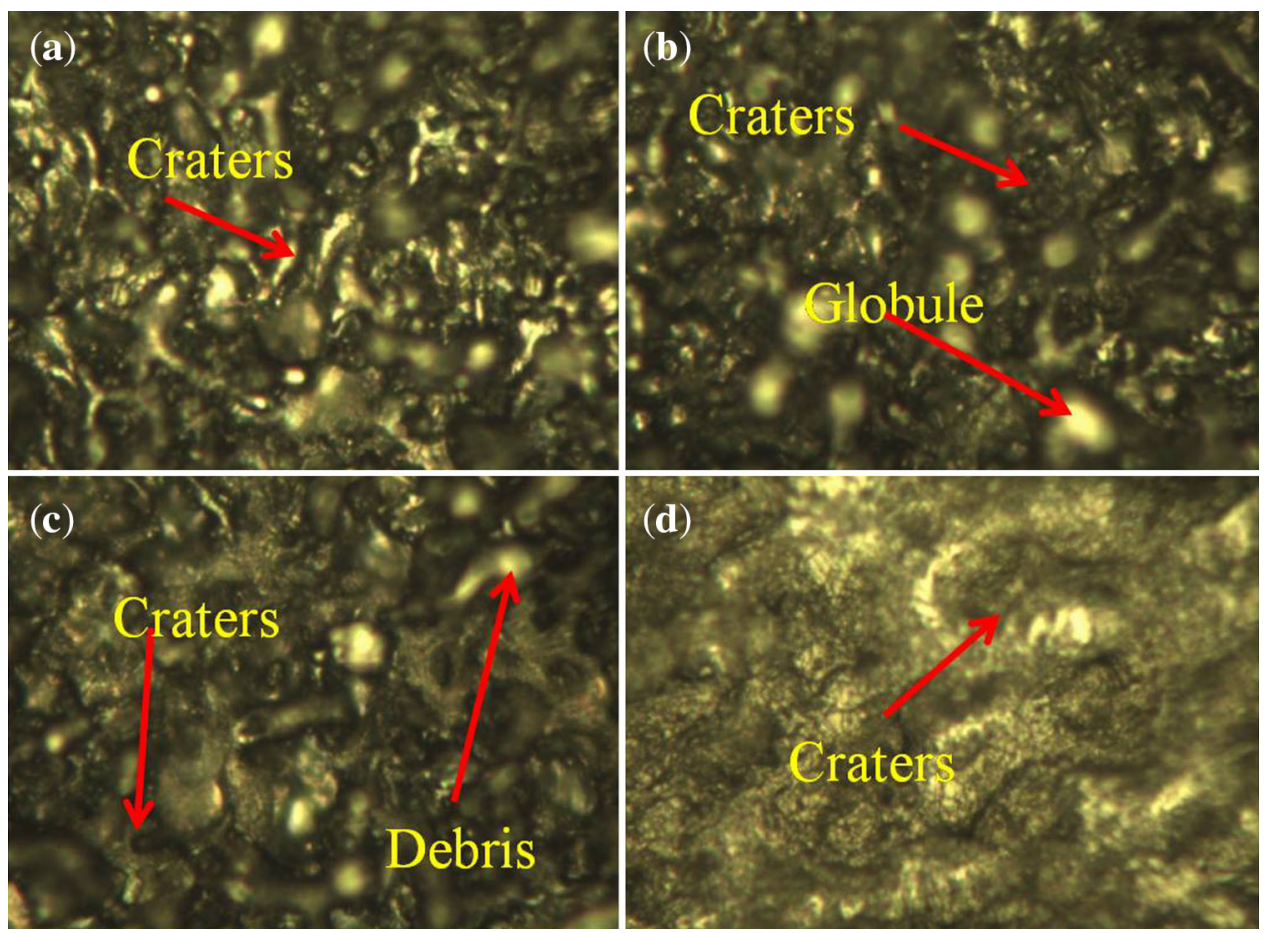

Figure 28. Optical micrograph $(\times 500$ to $\times 1000)$ of varying size of craters, debris, and globule rims at higher pulse on time and low pulse off time.
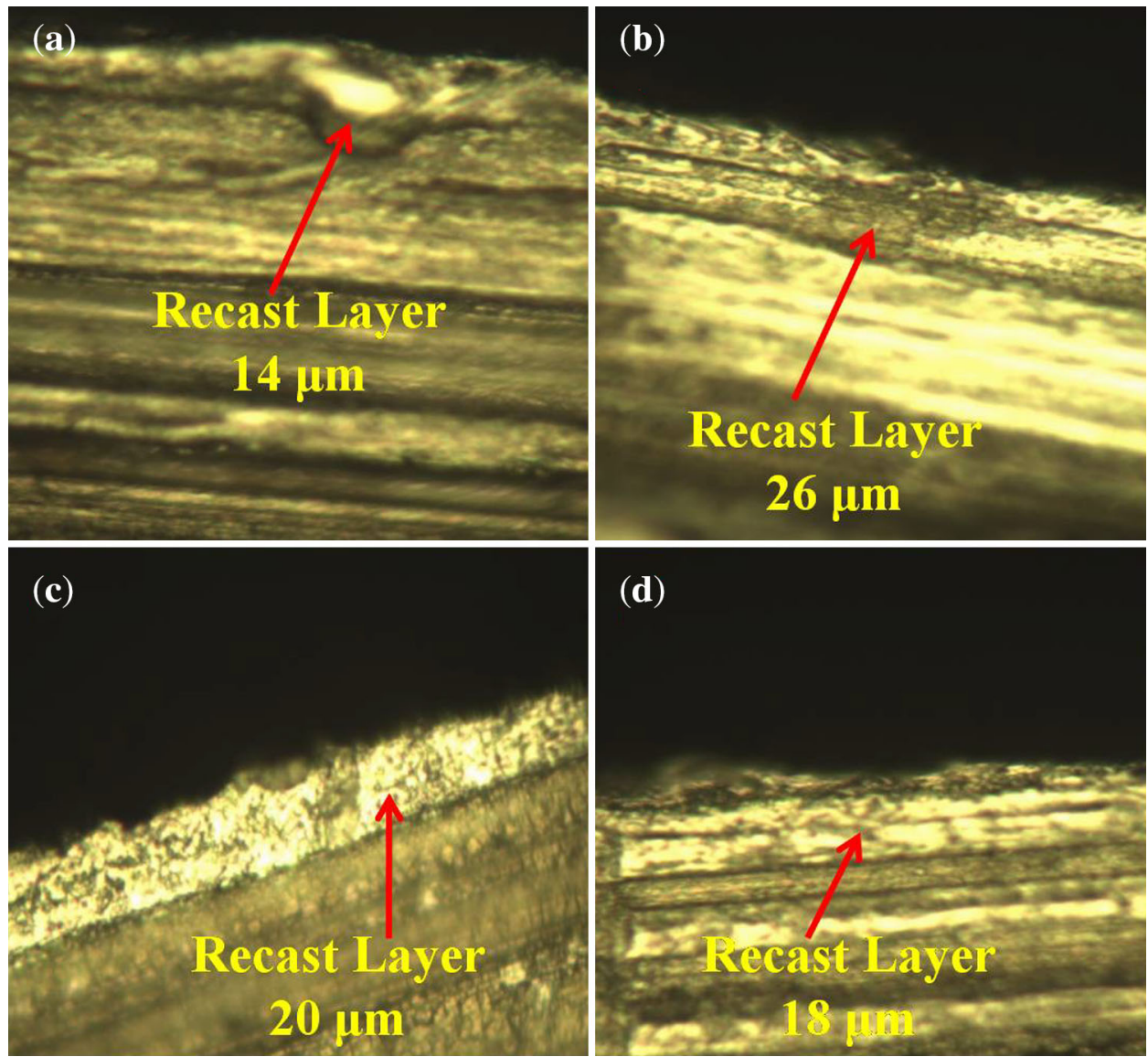

Figure 29. Cross-sectional optical micrographs of recast layer. 


\section{Acknowledgements}

The authors acknowledge M. M. University MullanaAmbala, Haryana, India, for providing the necessary WEDM set-up for experimentation. The authors are also thankful to Mr. Pawan for providing help in the laboratory.

\section{References}

[1] Dinda G P, Dasgupta A K and Mazumder J 2009 Laser aided direct metal deposition of Inconel 625 superalloy: microstructural evolution and thermal stability. Mater. Sci. Eng. A. 509(1-2): 98-104

[2] Paul C P, Ganesh P, Mishra S K, Bhargava P, Negi J and Nath A K 2007 Investigating laser rapid manufacturing for Inconel-625 components. Opt. Las. Tech. 39(4): 800-805

[3] Singh V K and Singh S 2015 Multi-objective optimization using Taguchi based Grey relational analysis for wire EDM of Inconel 625. J. Mater. Sci. Mech. Eng. 2(11): 38-42

[4] Chopde I K, Gogte C and Milind D 2014 Modeling and optimization of WEDM parameters for surface finish using design of experiments. In: Proceedings of the International Conference on Industrial Engineering and Operations Management, Bali, Indonesia

[5] Huang Yu, Ming Wuyi, Guo Jianwen, Zhang Zhen, Liu Guangdou, Li Mingzhen, and Zhang Guojun 2013 Optimization of cutting conditions of YG15 on rough and finish cutting in WEDM based on statistical analyses. Int. J. Adv. Manuf. Technol. 69(5): 993-1008

[6] Akbar A L and Saeed D 2013 The effect of operational cutting parameters on Nitinol-60 in wire electrodischarge machining. Adv. Mater. Sci. Eng. 457186: 6. doi:10.1155/ 2013/457186

[7] Zhang G, Zhang Z, Ming W, Guo J, Huang Yu and Shao X 2013 The multi-objective optimization of medium-speed WEDM process parameters for machining SKD11 steel by the hybrid method of RSM and NSGA-II. Int. J. Adv. Manuf. Technol. 70(9): 2097-2109

[8] Narendranath S, Manjaiah M, Basavarajappa S and Gaitonde V N 2013 Experimental investigations on performance characteristics in wire electro discharge machining of Ti50Ni42.4Cu7.6 shape memory alloy. Proc. I. Mech. Eng. Part B: J. Eng. Manuf. 227(8):1180-1187

[9] Gupta K and Jain N K 2014 Analysis and optimization of surface finish of wire electrical discharge machined miniature gears. Proc. I. Mech. Eng. Part B: J. Eng. Manuf. 228(5): 673-681

[10] Kumar Anish, Kumar Vinod and Kumar Jatinder 2013 Multiresponse optimization of process parameters based on response surface methodology for pure Titanium using WEDM process. Int. J. Adv. Manuf. Technol. 68: 2645-2668
[11] Taweel T El and Hewid A 2012 Parametric study and optimization of WEDM parameters for CK45 steel. Int. J. Adv. Eng. Appl. 1(4): 47-61

[12] Garg R 2010 Effect of process parameters on performance measures of wire electrical discharge machining. Ph.D. Thesis, Mechanical Engineering Department National Institute of Technology, Kurukshetra, India

[13] Sharma P, Chakradhar D and Narendranath S 2015 Multiresponse optimization of WEDM process using hybrid approach while machining Inconel 625 superalloy. J. Mach. Form. Technol. 6(3-4): 1947-4369

[14] Rodge M K, Sarpate S S and Sharma S B 2013 Investigation on process response and parameters in wire electrical discharge machining of Inconel 625. Int. J. Mech. Eng. Technol. 4(1): 54-65

[15] Rajyalakshmi G and Venkata Ramaiah P 2013 Multiple process parameter optimization of wire electrical discharge machining on Inconel 825 using Taguchi grey relational analysis. Int. J. Adv. Manuf. Technol. 69: 1249-1262

[16] Ramakrishna R and Karunamoorthy L 2008 Modeling and multi response optimization of Inconel-718 on machining of CNC WEDM process. J. Mater. Process. Technol. 207: 343-349

[17] Newton T R, Melkote S N, Watkins T R, Trejo R M and Reister L 2009 Investigation of the effect of process parameters on the formation and characteristics of recast layer in wire-EDM of Inconel 718. Mater Sci. Eng. 513-514: 208-215

[18] Hewidy M S, El-Taweel T A and El-Safty M F 2005 Modelling the machining parameters of wire electrical discharge machining of Inconel-601 using RSM. J. Mater. Process. Technol. 169: 328-336

[19] Jain V K, Rao Sreenivasa P, Choudhary S K and Rajurkar K P 1991 Experimental investigations into traveling wire electrochemical spark machining (TW-ECSM) of composites. J. Manuf. Sci. Eng. 113(1): 75-84

[20] Montgomery D C 2002 Design and analysis of experiments, 4th edition, New York: Wiley

[21] Gunaraj V and Murugan N 1999 Application of response surface methodologies for predicting weld base quality in submerged arc welding of pipes. J. Mater. Process. Technol. 88: 266-275

[22] Kwak J S 2005 Application of Taguchi and response surface methodologies for geometric error in surface grinding process. Int. J. Mach. Tool. Manuf. 45: 327-334

[23] Kim Chang-Ho and Kruth J P 2001 Influence of the electrical conductivity of dielectric on WEDM of sintered carbide. KSME. 15(12): 1676-1682

[24] Pandey P C and Shan H S 1980 Modern machining processes, 45th reprint 2012, New Delhi: Tata McGraw Hill

[25] Derringer G and Suich R 1980 Simultaneous optimization of several response variables. J. Q. Technol. 12: 214-219

[26] Kumar Anish, Kumar Vinod and Kumar Jatinder 2014 Microstructure analysis and material transformation of pure titanium and tool wear surface after wire electric discharge machining. Mach. Sci. Technol. 18 (1): 47-77 